\title{
Variações na Vazão do Rio Santo Antônio, Relação com o Pantanal Marimbus e a Importância para a Biodiversidade na Região do Parque Nacional da Chapada Diamantina/BA
}

\author{
Cezar Neubert Gonçalves ${ }^{1}$
}

Recebido em 15/09/2020 - Aceito em 27/05/2021

1 Parque Nacional da Chapada Diamantina/ICMBio, Brasil. <cezarngoncalves@gmail.com>.

RESUMO - O rio Santo Antônio é um afluente da margem esquerda do rio Paraguaçu, e forma, em seu baixo curso, a área alagada chamada Marimbus. Há relatos de que a vazão desse rio estaria sendo reduzida. Neste trabalho, realizou-se uma análise qualiquantitativa da variação da vazão $(\Delta \mathrm{Q})$ no rio Santo Antônio ao longo de 57 anos e oito meses, com dados de uma estação fluviométrica em Andaraí. Os dados foram sistematizados e analisados com correlações de Pearson $(\alpha=0,05)$, comparando-as com a variação na pluviometria $(\Delta \mathrm{P})$ em uma estação meteorológica da sub-bacia do rio Santo Antônio. Os valores de $\Delta \mathrm{Q}$ entre 1950 e 1970 apresentaram amplitudes que foram de $-0,8036$ a 4,8386, com $57,92 \%$ dos registros $\Delta \mathrm{Q}<0$. Entre 1971 até $2018, \Delta \mathrm{Q}$ variou de $-0,9591$ a 2,5644 , com 74,31\% dos registros $\Delta \mathrm{Q}<0$. A comparação $\Delta \mathrm{Q}$ e $\Delta \mathrm{P}$ entre 1950 e 2018 mostrou-se estatisticamente significativa $\left(r=0,341 ; R^{2}=0,1163 ; p=0,0116\right)$. Dados bibliográficos mostraram um aumento da área ocupada por culturas que utilizam intensamente água do rio, como banana (Musa sp). A revisão da bibliografia publicada sobre o Marimbus mostra cinco trabalhos botânicos na região, além de dez espécies, como Moenkhausia diamantina Benine et al., 2007; Parotocinclus adamanteus Pereira et al. (2019) e Astyanax lorien Zanata et al. (2018), por exemplo, e uma subfamília de peixes (Copionodontinae), endêmicas da região e áreas vizinhas. A fauna local é diferenciada em relação ao que existe nas regiões circunvizinhas. Desta forma, é necessário que a captação de água do rio Santo Antônio seja gerenciada de modo a evitar que a vazão deste curso d'água continue a diminuir.

Palavras-chave: Hidrografia; balanço hídrico; bacia do rio Paraguaçu; crise hídrica.

\section{Variations in the Flow of the Santo Antônio River, Relation with the Pantanal Marimbus and the Importance for Biodiversity in the Chapada Diamantina/BA National Park Region}

ABSTRACT - The Santo Antônio river is a tributary of the Paraguaçu river and forms, in its low course, a flooded area called Marimbus. There are reports that the flow of this river is being reduced. In this work, a qualitative and quantitative analysis of the flow variation $(\Delta \mathrm{Q})$ in the Santo Antônio river was carried out over 58 years, with data from a fluviometric station in Andaraí. The data were systematized and analyzed using Pearson correlations, comparing them with the variation in rainfall $(\Delta \mathrm{P})$ in a meteorological station in the sub-basin. The values of $\Delta \mathrm{Q}$ between the 1950s and 1970s showed amplitudes ranging from -0.8036 to 4.8386 , with $57.92 \%$ of the $\Delta \mathrm{Q}$ records $<0$. Between the 1980s and 2018, $\Delta \mathrm{Q}$ ranged from $-0,9591$ to 2.5644 , with $74.31 \%$ of the $\Delta \mathrm{Q}$ records $<0$. The comparison $\Delta \mathrm{Q}$ and $\Delta \mathrm{P}$ between 1950 and 2018 proved to be statistically significant $\left(r=0.341 ; R^{2}=0.1163 ; p=0.0116\right)$. The data showed a reduction in the river flow correlated mainly with the rainfall variation. Bibliographic data showed an increase in the area occupied by crops that make intensive use of river water, such as bananas. A review of the published bibliography on Marimbus shows five botanical works in the region. There are, also, seven species and a subfamily of fish endemic to the region and neighboring areas. The local fauna is different from what exists in the surrounding regions. Thus, it is necessary that the water intake from the Santo Antônio river be managed to prevent the flow of this watercourse from continuing to decrease.

Keywords: Hydrography, water balance, Paraguaçu river basin, water crisis. 


\title{
Variaciones en el Caudal del Río Santo Antônio, Relación con el Pantanal Marimbus e Importancia para la Biodiversidad en la Región del Parque Nacional Chapada Diamantina/BA
}

\begin{abstract}
RESUMEN - El río Santo Antônio es afluente de la margen izquierda del río Paraguaçu y forma, en su curso bajo, la zona inundada denominada Marimbus. Hay informes de que se está reduciendo el caudal de este río. En este trabajo se realizó un análisis cualitativo y cuantitativo de la variación de caudal $(\Delta \mathrm{Q})$ en el río Santo Antônio a lo largo de 57 años y ocho meses, con datos de una estación fluviométrica en Andaraí. Los datos fueron sistematizados y analizados con correlaciones de Pearson ( $\alpha=0.05)$, comparándolos con la variación de la precipitación $(\Delta \mathrm{P})$ en una estación meteorológica en la subcuenca del río Santo Antônio. Los valores de $\Delta \mathrm{Q}$ entre 1950 y 1970 mostraron amplitudes que van desde -0.8036 a 4.8386 , con un $57.92 \%$ de los registros $\Delta Q<0$. Entre 1971 a $2018, \Delta Q$ varió de -0.9591 a 2,5644 , con $74.31 \%$ de los registros $\Delta \mathrm{Q}<0$. La comparación $\Delta \mathrm{Q}$ y $\Delta \mathrm{P}$ entre 1950 y 2018 resultó ser estadísticamente significativa $\left(r=0.341 ; R^{2}=0.1163 ; p=0.0116\right)$. Los datos bibliográficos mostraron un aumento en el área ocupada por cultivos que utilizan intensamente el agua de los ríos, como el banano (Musa sp). La revisión de la bibliografía publicada sobre Marimbus muestra cinco trabajos botánicos en la región, además de diez especies, como Moenkhausia diamantina Benine et al. (2007); Parotocinclus adamanteus Pereira et al. (2019); y Astyanax lorien Zanata et al. (2018), por ejemplo, y una subfamilia de peces (Copionodontinae) endémica de la región y áreas vecinas. La fauna local es diferente a la existente en las regiones circundantes. Por tanto, es necesario que se gestione la captación de agua del río Santo Antônio para evitar que el caudal de este curso de agua siga disminuyendo.
\end{abstract}

Palabras clave: Hidrografía, balance hídrico, cuenca del río Paraguaçu, crisis hídrica.

\section{Introdução}

O Parque Nacional da Chapada Diamantina (PNCD) está situado no centro do estado da Bahia e abrange uma série de ambientes típicos de cerrado e da mata atlântica (ICMBio, 2007; Couto et al., 2011). Além disso, inclui também uma área alagada com cerca de 4.800 hectares conhecida como Marimbus, cuja flora é semelhante à encontrada no Pantanal Mato-grossense (França et al., 2010). O Marimbus é formado pela confluência dos rios Utinga, São José, Roncador e Garapa, que confluem para o rio Santo Antônio na área do PNCD (SEI, 2000).

O rio Santo Antônio e os rios Utinga e São José têm sido objeto de remoção de água para irrigação em projetos agrícolas. Denúncias encaminhadas à gestão do PNCD dão conta de que a sobre-exploração dos recursos hídricos estaria causando a redução do volume de água na área alagada, trazendo ameaças para a manutenção dos ecossistemas desta unidade de conservação, principalmente dos ambientes aquáticos que caracterizam o Marimbus. No entanto, não foi possível encontrar na literatura consultada publicações que demonstrassem a variação da vazão desse rio, o que permitiria uma avaliação da situação e daria parâmetros para o seu acompanhamento, uma vez que a retirada de água dos rios Santo Antônio, São José e Utinga, que ficam a montante do PNCD, traz consequências diretas para essa unidade de conservação. No caso do rio Santo Antônio, a retirada de água sem critérios para a irrigação de áreas agrícolas vizinhas, como referido por Aranzabal \& Oliveira (2019), pode trazer a redução significativa no volume do rio e pode prejudicar a dinâmica natural do pantanal Marimbus.

Este trabalho tem por objetivo fazer uma análise qualiquantitativa da variação da vazão do rio Santo Antônio com base em dados históricos de uma estação fluviométrica situada na cidade de Andaraí. Os resultados foram comparados com os dados climatológicos de uma estação meteorológica situada na sub-bacia do rio Santo Antônio. Também é apresentada e discutida uma revisão dos dados publicados até o momento sobre o pantanal Marimbus.

\section{Material e Métodos}

O rio Santo Antônio é um dos tributários da margem esquerda do rio Paraguaçu, considerado o principal rio cuja bacia hidrográfica fica localizada exclusivamente dentro dos limites do estado da Bahia, ocupando $54.877 \mathrm{~km}^{2}$ (SEI, 2000). A sub-bacia do rio Santo Antônio ocupa cerca de 


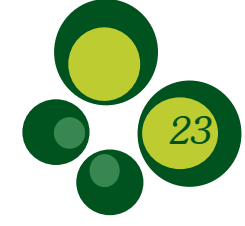

$9.400 \mathrm{~km}^{2}$, ou, aproximadamente, $17 \%$, da bacia do Paraguaçu (Figura 1).

Ao todo, o rio Santo Antônio tem, em média, $211 \mathrm{~km}$ de extensão desde a nascente mais distante, em Piatã, com o nome de Cochó (SEI, 2000; Figura 1). O rio Santo Antônio, como compreendido pela sociedade local, é formado pela confluência de três cursos d'água: o rio Cochó, que nasce no município de Piatã e percorre cerca de $120 \mathrm{~km}$ de extensão até encontrar, em sua margem direita, o rio Preto, cujas nascentes ficam em Palmeiras e tem cerca de $37 \mathrm{~km}$ de extensão. Aproximadamente $10 \mathrm{~km}$ adiante, esse curso d'água encontra, na sua margem esquerda, o rio Pratinha, que tem cerca de $71 \mathrm{~km}$ de extensão e cujas nascentes ficam no município de Iraquara. A partir desse ponto, o curso d'água passa a ser conhecido como rio Santo Antônio. Não foi possível identificar uma razão para a mudança nomenclatural no rio (de Cochó para Santo Antônio), mas após esse ponto são percorridos mais $81 \mathrm{~km}$ até a foz no rio Paraguaçu, no município de Andaraí. Além dos rios citados, são afluentes do Santo Antônio os rios Utinga, Mucugezinho, São José, Roncador e Garapa, além de outros de menor porte.

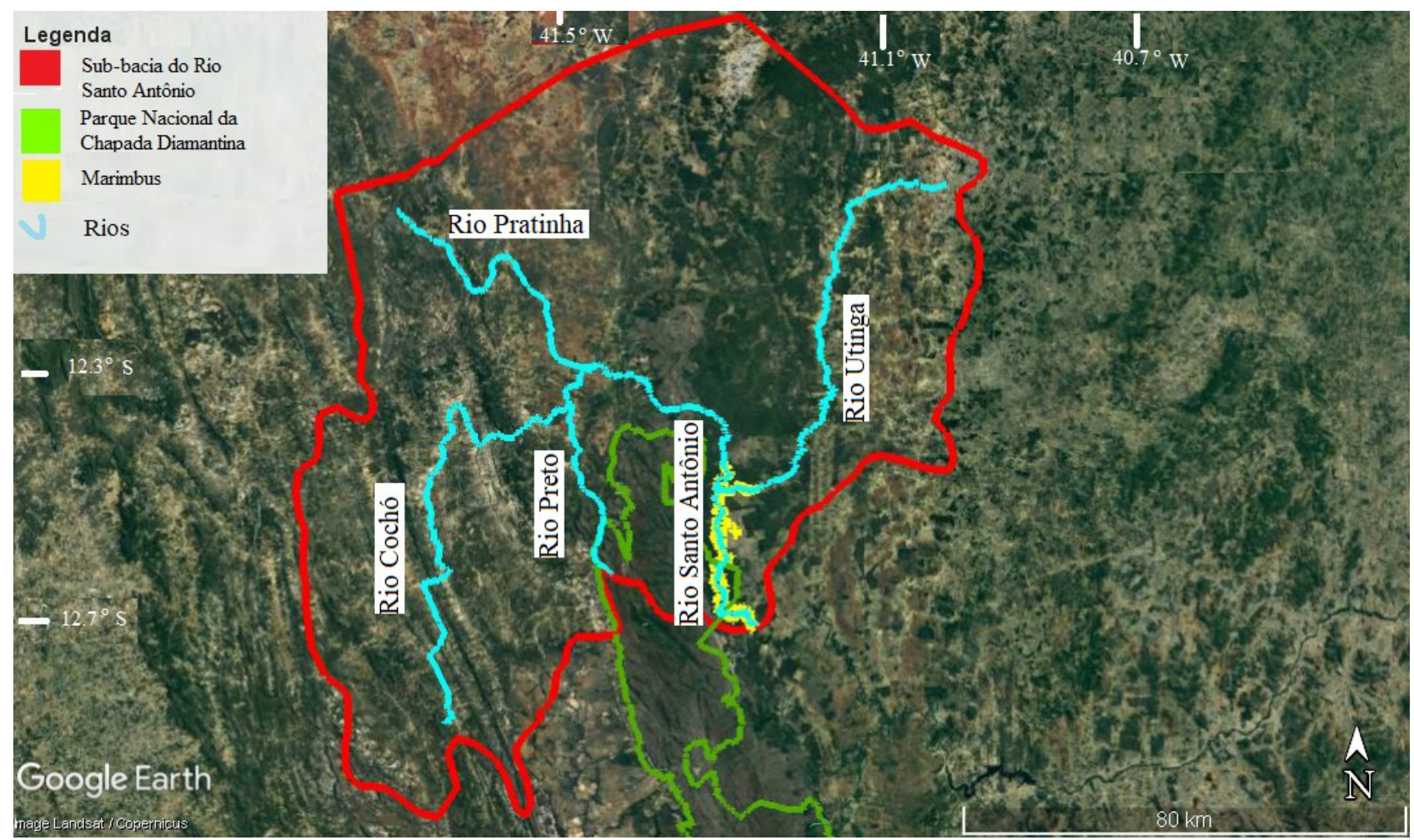

Figura 1 - Sub-bacia hidrográfica do rio Santo Antônio, Bacia hidrográfica do rio Paraguaçu, estado da Bahia. Estão destacados, também, os rios e os polígonos do Parque Nacional da Chapada Diamantina e a região alagada conhecida como Marimbus.

Entre os municípios de Lençóis e Andaraí, o rio se espraia em uma planície de alagamento que forma o Marimbus, uma área pantanosa com cerca de 4.800 hectares (Figura 2), dos quais 1.100 hectares dentro dos limites do PNCD (ICMBio, 2007). O termo marimbu é provavelmente de origem africana e significa pântano, brejo a margem de rios (Aulete, 2020) ou terra de roça (Marimbus, 2015). O termo é usado por Guimarães Rosa (1956) em várias passagens do livro Grande Sertão Veredas (páginas 53, 66, 276, 291, 299 e 413). No caso da Chapada Diamantina, o "s" acrescentado ao final da palavra provavelmente tem relação com a grande extensão do alagado, formado por várias áreas alagadas interconectadas. 


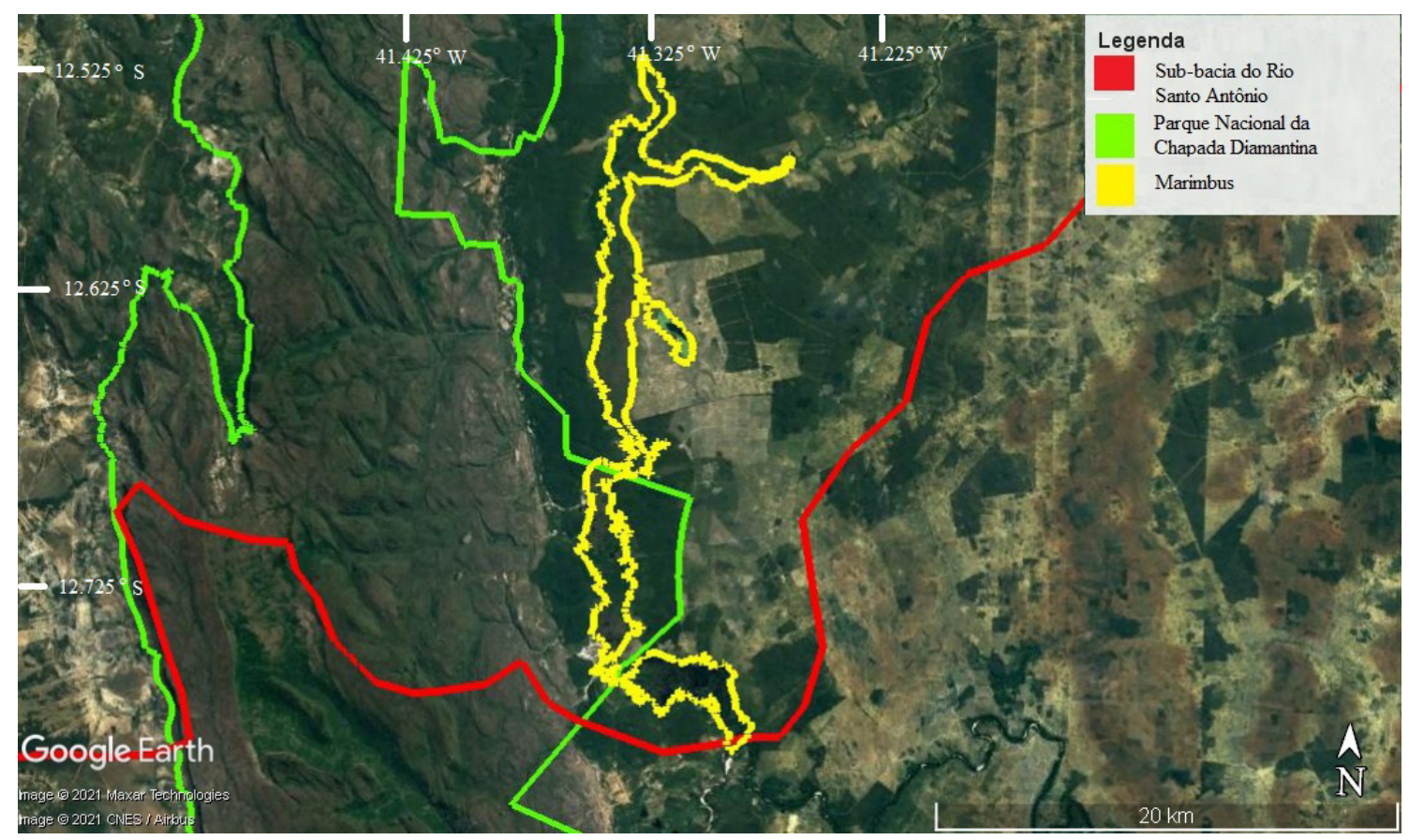

Figura 2 - Região alagada do Marimbus (polígono amarelo), na sub-bacia do rio Santo Antônio, bacia do rio Paraguaçu, estado da Bahia. São mostrados, também, os polígonos do Parque Nacional da Chapada Diamantina e da sub-bacia do rio Santo Antônio.

O site da Agência Nacional das Águas aponta a existência de 14 estações fluviométricas na sub-bacia do rio Santo Antônio, oito delas com dados disponíveis (Bonito, Código 51166000; Sítio Bambu, 51167000; Boninal, 51121000; Cochó dos Malheiros, 51135000; Seabra, 51130000; Utinga, 51170000; Wagner, 51158000; e Fertém, 51190000). Informações fornecidas pelo órgão estadual de licenciamento do estado da Bahia, o Instituto de Meio Ambiente e Recursos Hídricos (INEMA) (dados não publicados), dão conta de que as outorgas de água na bacia do rio Santo Antônio são fornecidas tendo como base a estação fluviométrica 51190000, no município de Andaraí, nas coordenadas UTM 24L 247140 E; 8588684 S. Essa estação fluviométrica fica a cerca de $6,5 \mathrm{~km}$ da foz do rio Santo Antônio, no curso inferior do rio, após receber contribuições das chuvas orográficas que caem na Serra do Sincorá. Toda a área dessa serra localizada nesta sub-bacia fica dentro dos limites do PNCD. O regime de chuvas dessa área é muito diferente do registrado em outros pontos da sub-bacia, pois, segundo CPRM (1994), a região entre os municípios de Lençóis e Andaraí tem médias pluviométricas anuais acima de $1400 \mathrm{~mm}$, enquanto as áreas a oeste da Serra do Sincorá, onde ficam as nascentes desse rio, têm menos de $800 \mathrm{~mm}$ de média de chuva anual.

Os dados da estação fluviométrica 51190000 (ANA, 2020) utilizados neste estudo são relativos a um período de 71 anos (1947/2018). Como citado, essa estação fica localizada junto à ponte do Fertém, no município de Andaraí, próximo a foz do rio Santo Antônio. A planilha disponível no site da ANA (http://www.snirh.gov.br/hidroweb/) contém dados de nível de consistência, cota, vazão, área molhada, largura e profundidade. As coletas de dados foram realizadas periodicamente, mas o histórico de coletas mostra que essa periodicidade variou muito ao longo do tempo (Tabela 1). As informações coletadas nas oito décadas indicaram que, entre 1960 e 1970, as amostragens foram mais intensas do que nas décadas de 1940, 1950, 1980, 1990, 2000 e 2010.

A planilha disponibilizada no site da ANA (2020) foi tratada, visando ordenar os dados que, em vários pontos da planilha, estavam fora de ordem cronológica, e eliminar redundâncias (Anexo 1). Na maioria das datas em que houve coleta, foram realizadas mais de uma coleta diária, variando entre duas e quatro coletas, conforme Anexo 1. Para verificar se as diferenças entre duas 
Tabela 1 - Periodicidade e variação no número de coletas de dados na estação fluviométrica 51190000, localizada próximo à ponte do Fertém, rio Santo Antônio, município de Andaraí (ANA, 2020).

\begin{tabular}{|c|c|c|c|c|}
\hline Década & $\mathbf{N}^{\circ}$ Anos & $\mathbf{N}^{\circ}$ coletas & Média coletas anual & Observações \\
\hline $1941-1950$ & 3 & 4 & 1.3 & \\
\hline $1951-1960$ & 6 & 8 & 1.3 & \\
\hline $1961-1970$ & 10 & 63 & 6.3 & Falta 1990 \\
\hline $1971-1980$ & 10 & 76 & 7.6 & \\
\hline $1981-1990$ & 9 & 33 & 3.3 & Até agosto de 2018 \\
\hline $1991-2000$ & 10 & 31 & 3.4 & 2.7 \\
\hline $2001-2010$ & 10 & 27 & 2.8 & \\
\hline $2011-2018$ & 8 & 22 & & \\
\hline
\end{tabular}

coletas diárias eram estatisticamente significativas, utilizou-se o teste de Kolmogorov-Smirnov $(\mathrm{K}-\mathrm{S})$ para duas amostras ou testes de qui-quadrado $\left(\chi^{2}\right)$ para mais de duas amostras. Caso as diferenças não fossem estatisticamente significativas ( $p>0,05$ ), optou-se, por convenção, utilizar a primeira coleta diária dos dados.

Os dados foram submetidos a uma análise de correlação entre variáveis (Pearson, $\alpha=0,05$ ), para verificar se os autovalores de correlação eram significativos entre todas as variáveis. Caso os valores fossem significativos, seria possível utilizar apenas uma delas como referência para os valores de todas as demais. Neste caso, a vazão do curso d'água $(Q)$ foi escolhida como valor de referência devido ao fato de que essa variável é utilizada como referência para a outorga d'água.

Como os dados relativos à variação dos parâmetros fluviométricos se encontra disponível apenas na planilha da ANA (2020), optou-se por apresentar e descrever os dados da vazão do rio Santo Antônio em todas as datas disponíveis, com exceção das décadas de 1940 e 1950, devido ao pequeno número de registros disponíveis para estes períodos, respectivamente, quatro e oito registros. Esse procedimento permitiu indicar os eventos extremos registrados, tanto de enchentes como de seca. Foram elaborados gráficos que mostram a variação de $\mathrm{Q}$, tendo se optado por apresentar os dados organizados em períodos de 20 anos entre as décadas de 1960-1970 e 1980-1990, além do período de 17 anos e oito meses entre 2001 e 2018, totalizando 57 anos e oito meses.

A variação da vazão $(\Delta Q)$ nos 57 anos e oito meses considerados foi calculada para o rio Santo
Antônio, como proposto por Mortatti et al. (2004), utilizando a seguinte fórmula:

$$
\Delta \mathrm{Q}=\mathrm{Q}-\mathrm{Qm} / \mathrm{Qm},
$$

onde $\Delta \mathrm{Q}=$ variação da vazão hídrica, $\mathrm{Q}=$ vazão hídrica apurada em uma medição; $\mathrm{Qm}=$ média das vazões hídricas. Além dos valores obtidos para cada medição de $\mathrm{Q}$ disponível, foram calculados as médias anuais de $\Delta \mathrm{Q}$, sendo que valores de $\Delta \mathrm{Q}<0$ são menores que $\mathrm{Qm} ; \Delta \mathrm{Q}=0$ é igual a $\mathrm{Qm}$; e $\Delta \mathrm{Q}>0$ são maiores que $\mathrm{Qm}$.

Foram calculados os valores da pluviometria das décadas de 1960, 1970, 1980, 1990, 2000 e entre 2011 e 2018, para as quais havia dados disponíveis para a Estação Meteorológica de Lençóis, registrada no Instituto Nacional de Meteorologia sob o número 83242 (INMET, 2020). A escolha dessa estação foi devida ao fato de ser a única estação meteorológica oficial situada na sub-bacia hidrográfica do rio Santo Antônio. Os dados de precipitação foram utilizados para calcular a variação da precipitação ao longo das décadas citadas, utilizando a seguinte fórmula:

$$
\Delta \mathrm{P}=\mathrm{P}-\mathrm{Pm} / \mathrm{Pm},
$$

onde $\Delta \mathrm{P}=$ Variação na precipitação; $\mathrm{P}=$ precipitação anual; $\mathrm{Pm}=$ precipitação média. Os valores de $\Delta \mathrm{Q}$ e $\Delta \mathrm{P}$ foram comparados, tendo-se calculado a correlação de Pearson entre esses dois índices. Para esta análise, foi necessário excluir os anos de 1963, 1979, 1980 e 1990, para os quais não havia valores de Q na planilha de ANA (2020).

A literatura sobre o pantanal Marimbus foi revisada para fazer uma síntese do conhecimento científico publicado atualmente sobre essa 
região, que está próxima da foz do rio Santo Antônio, buscando subsidiar a discussão sobre a importância ecológica de seus ecossistemas.

\section{Resultados}

No Anexo 1 são apresentadas as informações obtidas da estação fluviométrica 51190000 (ANA, 2020). Ao longo dos 71 anos abrangidos pela planilha, há registro de coletas dados de vazão em 274 dias, sendo que em 149 (54,38\%) deles houve mais de uma coleta. A aplicação dos testes $\mathrm{K}-\mathrm{S}$ para os 139 dias com duas coletas, $e$ $\chi^{2}$, para os 10 dias com três ou quatro coletas, não revelou diferenças estatisticamente significativas entre as coletas diárias em nenhuma das datas. Desta forma, foram utilizados os dados da primeira coleta diária como referência para as análises subsequentes.

As correlações entre as seis variáveis disponíveis na planilha da ANA (2020) se mostraram altamente significativas (Tabela 2), o que permitiu o uso de apenas uma delas como referência para os dados fluviométricos da estação 511900000. Optou-se por utilizar a vazão por ser a variável considerada pelo órgão ambiental do estado da Bahia (INEMA) para a concessão de outorgas para o uso de água.

Tabela 2 - Correlações de Pearson, calculadas pelo programa Bioestat 5.3 (Ayres et al., 2007), entre as seis variáveis disponíveis nas planilhas da ANA (2020), acima da diagonal, e respectivas probabilidades (p), abaixo da diagonal, para a estação fluviométrica 511900000, situada na ponte do Fértem, rio Santo Antônio, no município de Andaraí, coordenadas UTM 24L 247140 E; 8588684 S. Considerouse como significativos valores de $\mathrm{p} \leq 0,05 . \mathrm{Q}=$ vazão; A.mol. = área molhada; V.média = velocidade média; Prof. = profundidade.

\begin{tabular}{|l|r|r|r|r|r|r|}
\hline & \multicolumn{1}{|c|}{ Cota } & \multicolumn{1}{c|}{$\mathbf{Q}$} & \multicolumn{1}{c|}{ A.mol. } & Largura & V.média & \multicolumn{1}{c|}{ Prof. } \\
\hline Cota & 1 & 0.88 & 0.92 & 0.37 & 0.65 & 0.80 \\
\hline Q & $<0.0001$ & 1 & 0.94 & 0.61 & 0.83 & 0.84 \\
\hline A.mol. & $<0.0001$ & $<0.0001$ & 1 & 0.65 & 0.73 & 0.89 \\
\hline Largura & $<0.0001$ & $<0.0001$ & $<0.0001$ & 1 & 0.41 & 0.31 \\
\hline V.média & $<0.0001$ & $<0.0001$ & $<0.0001$ & $<0.0001$ & 1 & 0.71 \\
\hline Prof. & $<0.0001$ & $<0.0001$ & $<0.0001$ & $<0.0001$ & $<0.0001$ & 1 \\
\hline
\end{tabular}

Os dados das décadas de 1960 e 1970 mostram a grande variabilidade existente na vazão do rio Santo Antônio. A menor vazão diária registrada neste período de vinte anos foi em 09 de novembro de $1962\left(0,88 \mathrm{~m}^{3} / \mathrm{s}\right)$ e a maior em 20 de abril de 1965 (143m³/s). Em média, a vazão do rio nesta época era 29,96 $\pm 26,19$ m³/s (Figura 3).

Nas décadas de 1980 e 1990, com um volume menor de coleta de informações, chama a atenção a menor amplitude dos dados (Figura 4). $\mathrm{O}$ maior volume registrado nesse período foi encontrado em 17 de fevereiro de 1982 (87,3m³/s). O menor registro foi encontrado em 17 de outubro de $1995\left(1,21 \mathrm{~m}^{3} / \mathrm{s}\right)$. Em média, foram registrados $21,34 \pm 21,36 \mathrm{~m}^{3} / \mathrm{s}$ no período.

Finalmente, no período compreendido entre o ano 2001 e 2018, a amplitude dos dados é similar ao período anterior. A maior cheia registrada no período ocorreu em 05 de abril de 2017 (Q = $73,15 \mathrm{~m}^{3} / \mathrm{s}$ ), e a menor vazão, em 16 de outubro de $2014\left(\mathrm{Q}=0,746 \mathrm{~m}^{3} / \mathrm{s}\right)$, que foi o menor valor registrado até o momento na série histórica considerada $\left(12,71 \pm 14,64 \mathrm{~m}^{3} / \mathrm{s}\right)$. Neste período de 18 anos, a tendência encontrada indicou uma diminuição do valor médio da vazão do rio Santo Antônio que, neste último período, foi 40,44\% menor que no período de 1980 a 1990 (Figura 5).

Os valores de $\Delta \mathrm{Q}$ obtidos para o rio Santo Antônio mostram que as primeiras décadas do período considerado (1950 a 1970) apresentaram amplitudes maiores de variação (entre -0,8036 e 4,8386 ), apresentando $57,92 \%$ dos registros com $\Delta \mathrm{Q}<0$. Nas últimas décadas (1980 até 2018), a amplitude da variação foi menor $(-0,9591$ a 2,5644 ), com $74,31 \%$ dos registros apresentando 
$\Delta \mathrm{Q}<0$ (Figura 6). A comparação entre $\Delta \mathrm{Q} e$ $\Delta \mathrm{P}$ entre os anos de 1950 e 2018 (Figura 7) mostrou-se estatisticamente significativa $(r=0,341$; $\left.\mathrm{R}^{2}=0,1163 ; \mathrm{p}=0,0116\right)$.

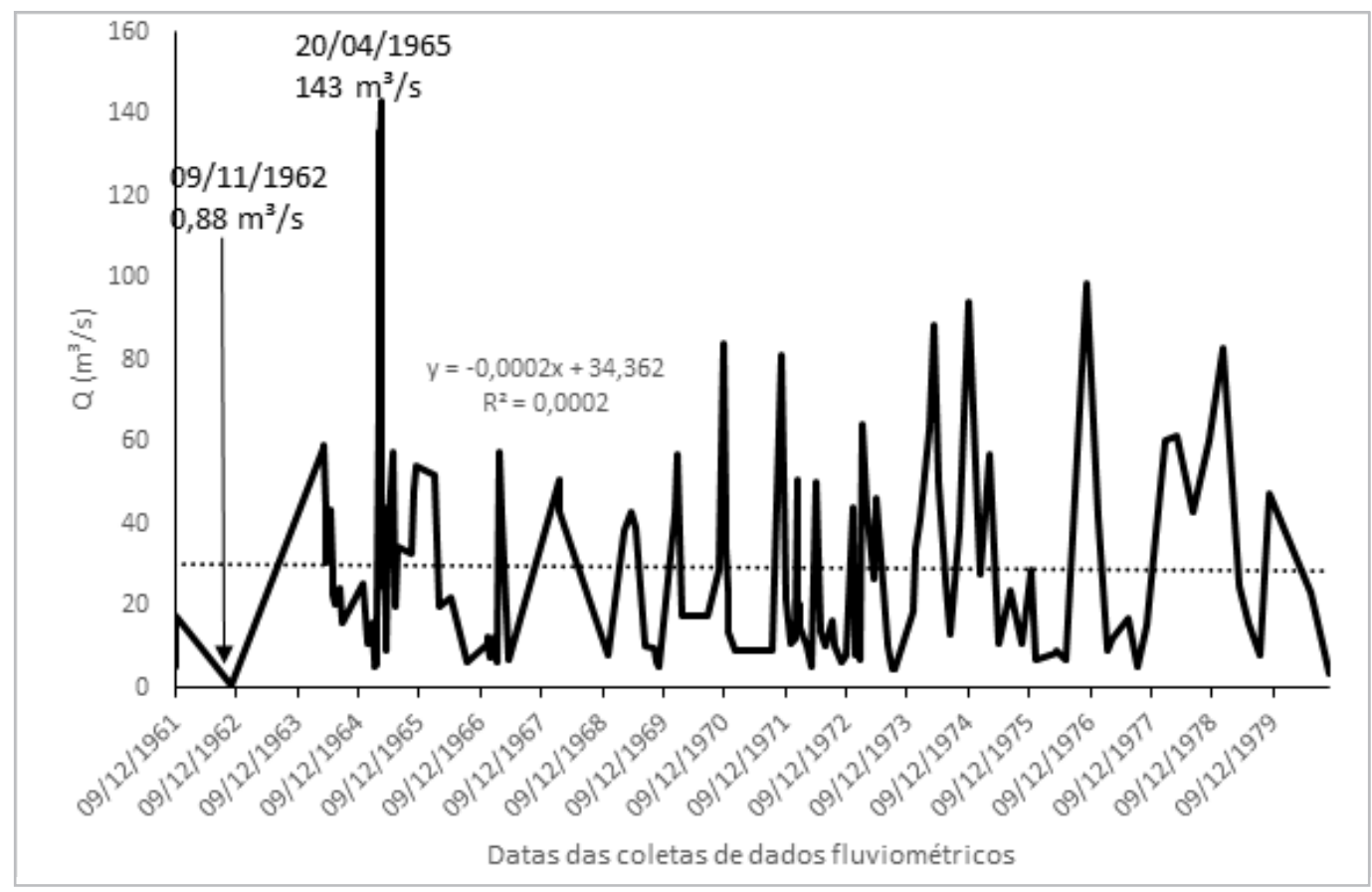

Figura 3 - Vazão (Q) no rio Santo Antônio, em m³/s, nas décadas de 1960 e 1970, com base em dados da estação fluviométrica 51190000 (ANA, 2020), localizada próximo à ponte do Fertém, rio Santo Antônio, município de Andaraí. São destacadas as datas com a menor e a maior vazão registradas no período. Também é mostrada a tendência dos dados (linha tracejada), com a respectiva equação e índice de determinação $\left(\mathrm{R}^{2}\right)$.

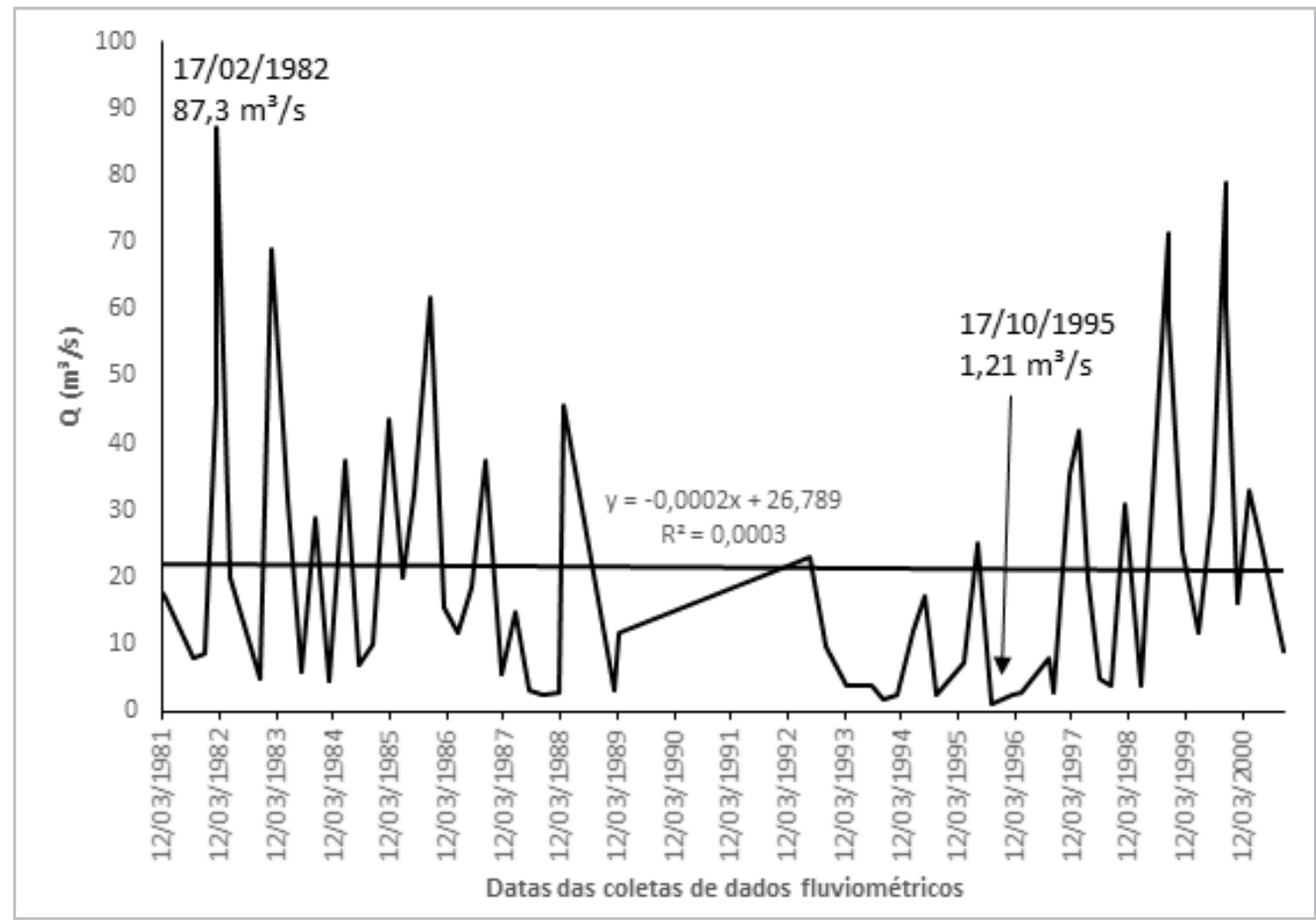

Figura 4 - Vazão (Q) no rio Santo Antônio, em m³/s, nas décadas de 1970 e 1990, com base em dados da estação fluviométrica 51190000 (ANA, 2020), localizada próximo à ponte do Fertém, rio Santo Antônio, município de Andaraí. São destacadas as datas com a menor e a maior vazão registradas no período. Também é mostrada a tendência dos dados (linha tracejada), com a respectiva equação e índice de determinação $\left(\mathrm{R}^{2}\right)$. 


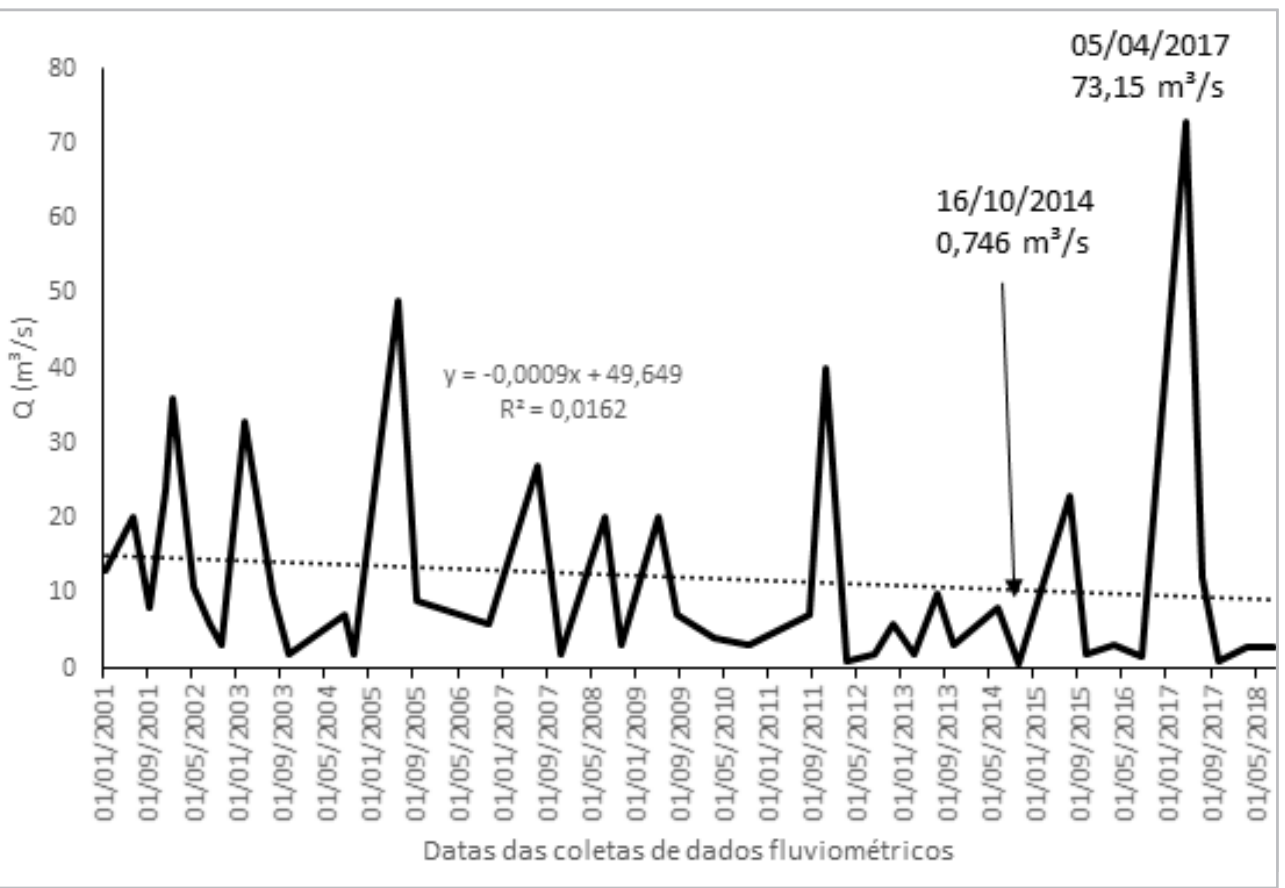

Figura 5 - Vazão (Q) no rio Santo Antônio, em m³/s, nas décadas de 2001 e 2018, com base em dados da estação fluviométrica 51190000 (ANA, 2020), localizada próximo à ponte do Fertém, rio Santo Antônio, município de Andaraí. São destacadas as datas com a menor e a maior vazão registradas no período. Também é mostrada a tendência dos dados (linha tracejada), com a respectiva equação $e$ índice de determinação $\left(\mathrm{R}^{2}\right)$.

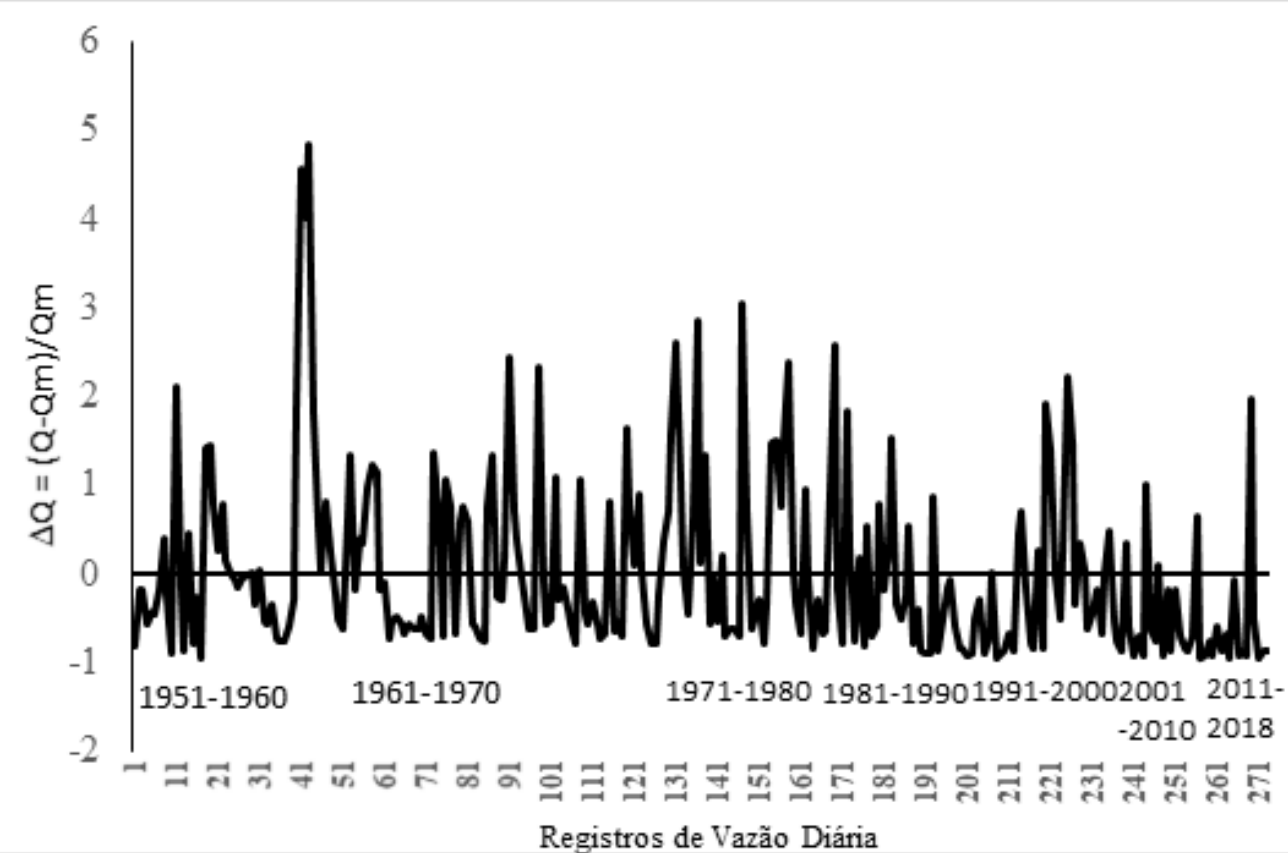

Figura 6 - Variação da vazão $(\Delta Q)$ do rio Santo Antônio, nas décadas de 1950 até 2000, além do período de 2010 a 2018, com base em dados da estação fluviométrica 51190000 (ANA, 2020), localizada próximo à ponte do Fertém, rio Santo Antônio, município de Andaraí. 


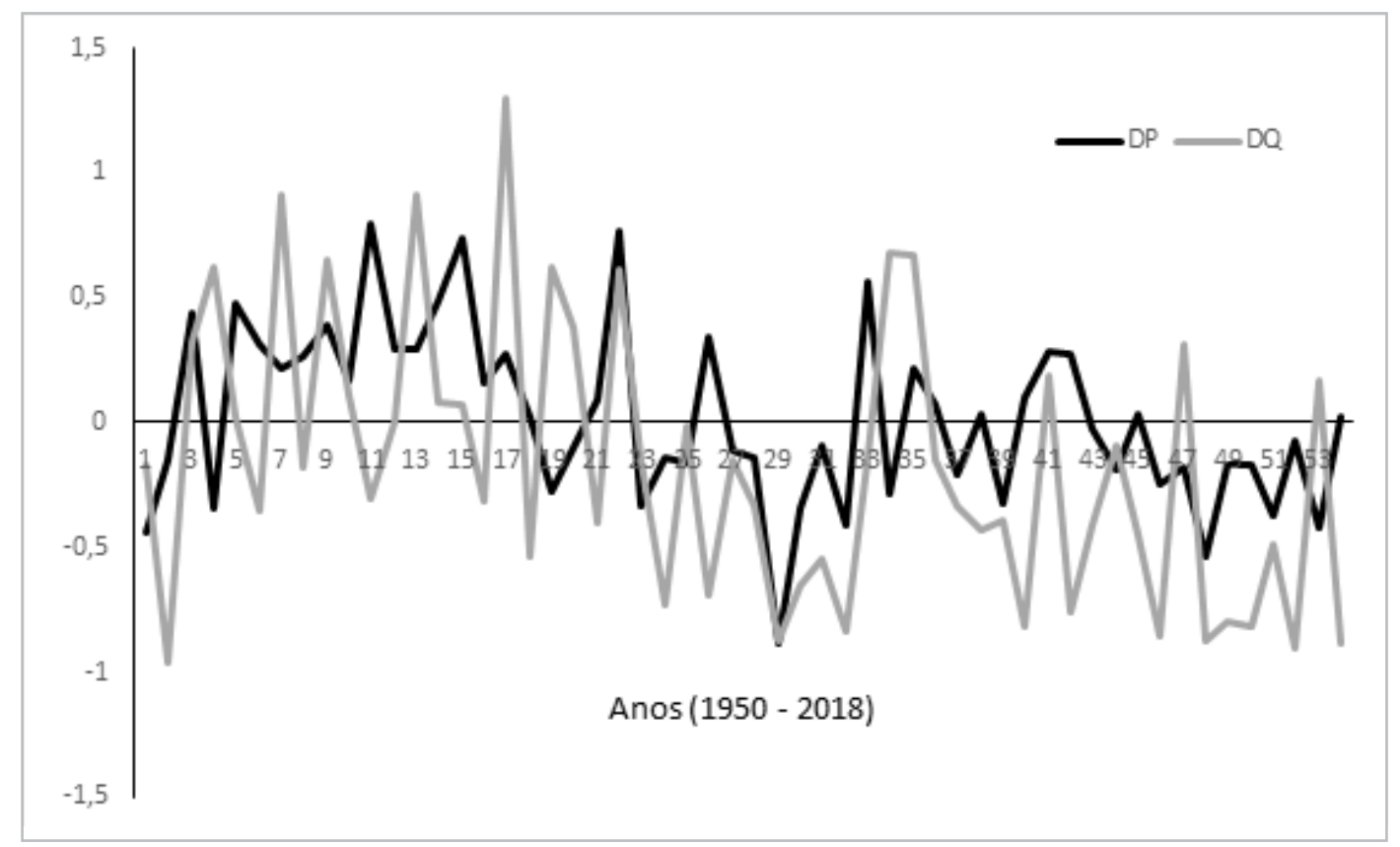

Figura 7 - Comparativo entre as variações da pluviometria $(\Delta \mathrm{P})$ e da vazão $(\Delta \mathrm{Q})$ no rio Santo Antônio. Os valores de pluviometria (precipitação) foram obtidos da estação meteorológica de Lençóis (INMET, 2020), entre as décadas de 1950 até 2010, além do período entre 2010 e 2018. Os dados de vazão são da estação fluviométrica 51190000 (ANA, 2020), localizada próximo à ponte do Fertém, rio Santo Antônio, município de Andaraí. $\Delta \mathrm{P}=\Delta \mathrm{P}, \Delta \mathrm{Q}=\Delta \mathrm{Q}$.

\section{Discussão}

Embora os 71 anos de registros de coletas de dados na estação fluviométrica 51190000 no rio Santo Antônio permitam reconstituir o comportamento desse curso d'água neste período, a variabilidade na frequência com que os dados foram coletados torna o registro imperfeito. Desta forma, é difícil saber se o maior registro de cheia neste rio, ocorrido em 20 de abril de 1965 $\left(143 \mathrm{~m}^{3} / \mathrm{s}\right)$, pode ser devido ao fato de que tenha sido efetivamente excepcional ou, então, com uma menor periodicidade na coleta de informações nas décadas seguintes, os eventos extremos acabaram não sendo registrados. De qualquer modo, nesse mesmo período, entre 1961 e 1980, houve cinco registros de eventos de cheia com $\mathrm{Q}>80 \mathrm{~m}^{3} / \mathrm{s}$, enquanto entre 1981 e 2000 foi registrado um único evento desta magnitude, em 17 de fevereiro de $1982\left(87,3 \mathrm{~m}^{3} / \mathrm{s}\right)$. Entre 2001 e 2018, não houve nenhum registro de cheias que atingissem $\mathrm{Q} \geq 80 \mathrm{~m}^{3} / \mathrm{s}$ (Figura 8 ).

Considerando os menores registros de vazão, houve apenas um registro de vazão com valores de $\mathrm{Q} \leq 2,0 \mathrm{~m}^{3} / \mathrm{s}$ nas décadas de $1960 \mathrm{e}$ 1970 (0,88m³/s em 09 de novembro de 1962), dois no período de 1980 até o ano 2000, e nove registros entre 2001 e 2018 (Figura 9). Esses dados indicaram uma redução na vazão do rio ao longo do período.

A tendência de redução na vazão do rio Santo Antônio também foi demonstrada quando se analisa $\Delta \mathrm{Q}$. A maior parte dos registros das últimas décadas apresentou $\Delta Q \leq 0$, indicando menores volumes d'água no rio, e a menor amplitude de $\Delta \mathrm{Q}$ foi provavelmente devida a menor ocorrência de grandes eventos de cheia, relatada acima.

A correlação entre $\Delta \mathrm{P} / \Delta \mathrm{Q}$ mostrou que, ao longo do período considerado, a precipitação foi o fator preponderante na redução dos níveis do rio Santo Antônio, como indicado pelos dados. Houve um período de seca intenso nos últimos anos, entre 2012 e 2017 (Lima \& Magalhães, 2018), que afetou toda a região Nordeste do Brasil. Dados obtidos da estação meteorológica do INMET em Lençóis indicam uma tendência de queda nos índices pluviométricos entre as décadas de 1970 e 2010 (Figura 8). Essas variações climáticas têm relação com a ocorrência de fenômenos El Niño (Chen et al., 2004; Kayano et al., 2015), além de outros fenômenos como a Oscilação Decadal do 
Pacífico (Molion, 2005), embora seja possível que haja pouca relação entre este último fenômeno e as variações climáticas no Nordeste do Brasil (Ávila \& Brito, 2015).

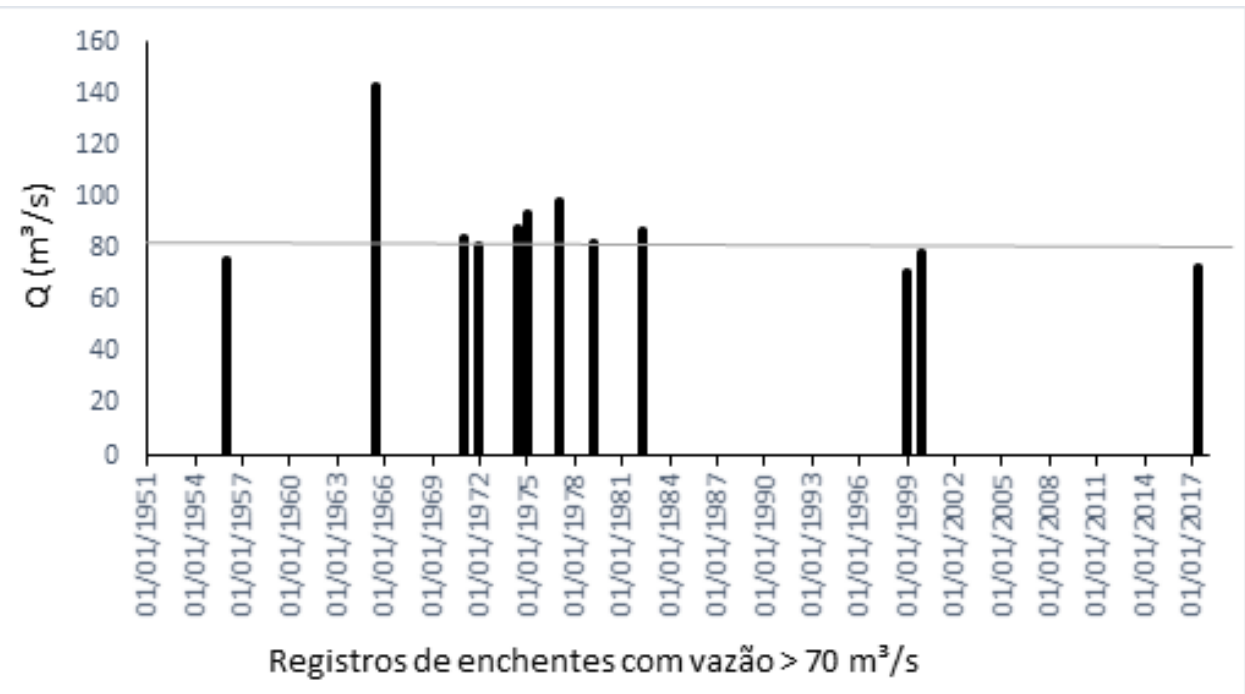

Figura 8 - Registros de enchentes no rio Santo Antônio, considerando vazões superiores a $70 \mathrm{~m}^{3} / \mathrm{s}$, entre 1950 e 2018, a partir de dados da estação fluviométrica 51190000 (ANA, 2020), localizada próximo à ponte do Fertém, rio Santo Antônio, município de Andaraí. A linha destacada na figura indica $\mathrm{Q}=80 \mathrm{~m}^{3} \mathrm{~s}$. Notar que não há nenhum registro acima deste valor após 1982.

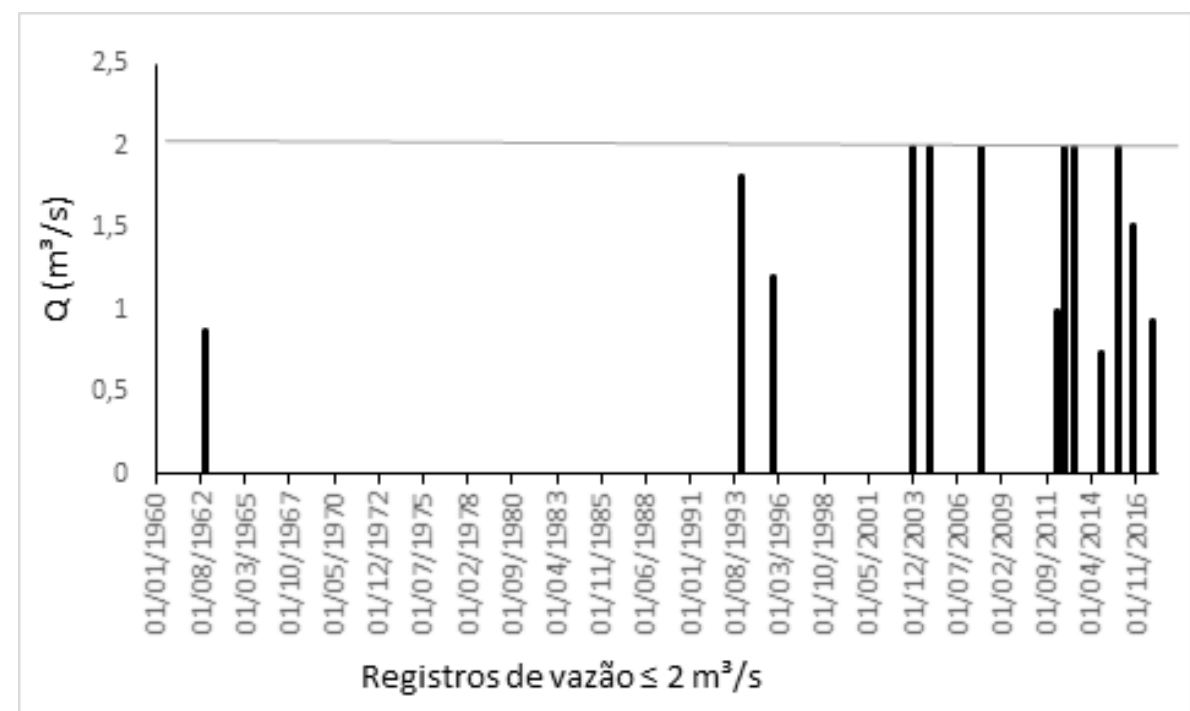

Figura 9 - Registros de vazão $\leq 2 \mathrm{~m} 3 / \mathrm{s}$ entre 1960 e 2018, a partir de dados da estação fluviométrica 51190000 (ANA, 2020), localizada próximo à ponte do Fertém, rio Santo Antônio, município de Andaraí. A linha destacada na figura indica $Q=2 \mathrm{~m}^{3} / \mathrm{s}$. Notar a concentração de registros $\mathrm{Q} \leq 2 \mathrm{~m}^{3} / \mathrm{s}$ após o ano de 1991.

Além da redução da precipitação apontada anteriormente, alterações no uso do solo na sub-bacia do rio Santo Antônio influenciaram na disponibilidade hídrica. A área plantada com bananas (Musa sp), na região marginal do rio Utinga, afluente do Santo Antônio, aumentou de cerca de 200 para mais de 1.000 hectares entre 2008 e 2018 (Oliveira, 2018). Além disso, há captações de água dos rios da sub-bacia para outras finalidades, sendo que apenas cerca de $30 \%$ delas está outorgada, sendo as $70 \%$ restantes clandestinas $e$, portanto, sem controle oficial (Aranzabal \& Oliveira, 2019). 
Essa situação é diferente da apontada por Pereira et al. (2007) para os rios da bacia do São Francisco, onde os autores indicaram, na época, o aumento na vazão dos cursos d'água analisados. Da mesma forma, Mortatti et al. (2004) encontraram variações positivas na vazão do rio Tietê, em São Paulo, em um período de 40 anos. Essas oscilações entre diferentes bacias hidrográficas, algumas com incremento no volume de água nos rios e outras com redução nos valores apurados, foram avaliadas por Alves et al. (2013), e podem ser creditadas principalmente a aspectos climáticos como a Oscilação Decadal do Pacífico ou a ocorrência de eventos de El Niño e La Niña.

\section{Aspectos ecológicos do Marimbus}

A extensa área alagada do Marimbus apresenta características ecológicas bastante distintas das áreas circundantes, embora haja uma forte interconexão entre as florestas estacionais semidecíduas vizinhas $e$ a vegetação existente na área alagada, onde predominam macrófitas aquáticas. Estas conexões são fundamentais para a manutenção da biodiversidade local, mas ainda são pouco compreendidas.

Dois fragmentos florestais da região, que totalizam 988 hectares de extensão e estão localizados a oeste do Marimbus, foram caracterizadas por Lima et al. (2016), que encontraram 111 espécies arbóreas como, por exemplo, Pouteria caimito (A. Ruiz \& Pavón) Radlk., Protium ovatum Engl., Simarouba amara Aubl. e Tapirira guianensis Aubl. Esse número é superior às 88 espécies arbóreas encontradas por Couto et al. (2011) em florestas similares em Lençóis, cerca de $26 \mathrm{~km}$ ao norte. Lima et al. (2016) indicaram que as florestas amostradas nessa área estão em estágio avançado de regeneração, conforme a Resolução CONAMA 05/1994 (CONAMA, 1994). Até o momento, esse foi o único estudo avaliando as florestas nas áreas circunvizinhas ao Marimbus.

A área alagada do Marimbus é ocupada por vegetação onde predominam macrófitas aquáticas, ou seja, plantas que conseguem sobreviver às condições de alagamento. França et al. (2010) fizeram um levantamento da flora de macrófitas na região e encontraram 130 espécies em 46 famílias, com predomínio de espécies submersas (39\% da flora) e emergentes (30\%), além de flutuantes (fixas e livres). Os autores destacaram a ocorrência de Echinodorus paniculatus Mich., Hydrocleys nymphoides (Willd.) Buch., Nymphaea amazonum Mart. \& Zucc., Nymphaea ampla L., Polygonum meisnerianum Cham. \& Schlecht., Salvinia auriculata Aubl., Salvinia oblongifolia Mart. e Utricularia foliosa L., entre outras espécies. A comparação da flora local com a de diversas áreas alagadas no Brasil encontrou mais semelhanças com a flora do Pantanal Mato-grossense do que com a flora de outras áreas alagadas do Nordeste do Brasil, o que justifica o uso do termo "minipantanal" para o Marimbus.

Ramos et al. (2016) avaliaram a composição específica de Hydrodictyaceae, uma família de algas microscópicas, que ocorrem nos rios da região. Os autores citam a ocorrência de nove espécies dessas algas, das quais seis citadas, pela primeira vez para o Nordeste do Brasil (Pediastrum angulosum (Ehrenb.) Menegh, P. argentinense Bourr. \& Tell, Sorastrum americanum (Bohlin) Schmidle, S. spinulosum Nägeli, Tetraedron caudatum (Corda) Hansg., T. minimum (A. Braun) Hansg.).

Entre as plantas fanerófitas que ocorrem no Marimbus, Gonçalves \& Azevêdo-Gonçalves (2016) analisaram as populações de Mauritia flexuosa L.f. na região norte do PNCD e indicaram que a população existente no rio São José, afluente do Santo Antônio, apresenta condições para expandir-se ao sul, ocupando áreas do Marimbus. Os autores também recomendaram que se fizessem esforços para aumentar o número de indivíduos da espécie para fazer frente à grande população de dendezeiros (Elaeis guineensis Jacq.) que ocorre no Marimbus. Esta última espécie, nativa da África (Venturieri et al., 2009), se desenvolve melhor em climas e ambientes úmidos (Carvalho, 2000), sendo favorecida pelas condições ambientais do Marimbus.

Lima et al. (2018) avaliaram a presença de metais pesados nas águas e em Salvinia auriculata Aubl. no Marimbus. Os autores indicaram os teores de metais pesados na região que estavam dentro do preconizado pela legislação brasileira para águas classe 1 , como preconizado na Resolução CONAMA 357/2005 (CONAMA, 2005), que permite o uso para consumo humano (após tratamento), irrigação ou uso recreativo. Os autores observaram, no entanto, que um dos pontos apresentava valores de zinco $(\mathrm{Zn})$ acima dos demais, e indicaram que provavelmente a origem desse metal seja os agrotóxicos que são 
aplicados em áreas rio acima, nos cursos superior e médio do rio Santo Antônio e de seus afluentes, uma vez que o Marimbus fica localizado no curso inferior desse rio.

A fauna do Marimbus apresenta características diferentes das áreas circundantes. Entre os peixes, há registros da ocorrência de diversas espécies endêmicas da sub-bacia do Santo Antônio (Tabela 3), com destaque para a subfamília Copionodontinae, com cinco espécies em dois gêneros, todas restritas a esta área. Outros peixes endêmicos da sub-bacia incluem duas espécies de piaba (Moenkhausia diamantina Benine et al., 2007 e Astyanax lorien Zanata et al., 2018), um cascudo (Parotocinclus adamanteus Pereira et al., 2019) e um bagre (Aspidoras psammatides Brito et al., 2005) (Santos \& Caramaschi, 2007). Além desses, há o registro da ocorrência de um acará (Geophagus diamantinensis Mattos et al., 2015) endêmico da bacia do alto Paraguaçu. O destaque negativo na ictiofauna local é a presença maciça de tucunarés (Cichla cf. temensis Humboldt, 1833) e apanharis (Astronotus ocellatus (Cuvier, 1829)). Essas duas espécies são peixes exóticos, oriundos da Amazônia, que causam sérios danos às espécies nativas devido à predação, especialmente C. cf. temensis, como analisado por Godinho \& Santos (2014).

Magalhães et al. (2015) citaram três espécies de répteis e anfíbios no Marimbus (Phrynops geoffroanus (Schweigger, 1812) cágado; Scinax fuscomarginatus (Lutz, 1925) e Dendropsophus nanus (Boulenger, 1889) - duas espécies de pererecas) em um levantamento sobre a herpetofauna do PNCD.

Não há estudos específicos sobre a mastofauna na área, mas inventários para o plano de manejo do PNCD (ICMBIO, 2007), indicaram a existência de lontras (Lontra longicaudis (Olfers, 1818)). Da mesma forma, não há pesquisas específicas para a avifauna, mas Parrini et al. (1999) citam 75 espécies de aves para o Marimbus em um check list sobre a avifauna da Chapada Diamantina, chamando a atenção para a presença de muitas aves aquáticas, como o como o mergulhão pequeno (Tachybaptus dominicus (Linnaeus, 1766)), o mergulhão caçador (Podilymbus podiceps (Linnaeus, 1758)), a garçabranca-grande (Ardea alba Linnaeus, 1758) e o socó-boi (Tigrisoma lineatum (Boddaert, 1783)).

Tabela 3 - Espécies de peixes endêmicos da sub-bacia do rio Santo Antônio, segundo Sarmento-Soares et al. (2020). Também foi incluído o acará, que é endêmico da bacia do rio Paraguaçu, e ocorre na sub-bacia.

\begin{tabular}{|l|l|l|}
\hline \multicolumn{1}{|c|}{ Nome popular } & \multicolumn{1}{|c|}{ Nome científico } & \multicolumn{1}{c|}{ Família (subfamília) } \\
\hline Jundiá & Copionodon lianae Campanario \& de Pinna, 2000 & Trichomycteridae (Copionodontinae) \\
\hline Jundiá & C. orthiocarinatus de Pinna, 1992 & Trichomycteridae (Copionodontinae) \\
\hline Jundiá & C. pecten de Pinna, 1992 & Trichomycteridae (Copionodontinae) \\
\hline Jundiá & Glaphyropoma rodriguesi de Pinna, 1992 & Trichomycteridae (Copionodontinae) \\
\hline Jundiá & G. spinosum Bichuette, de Pinna \& Trajano, 2008 & Trichomycteridae (Copionodontinae) \\
\hline Piaba & Moenkhausia diamantina Benine et al., 2007 & Characidae \\
\hline Cascudo & Parotocinclus adamanteus Pereira et al., 2019 & Locariidae \\
\hline Piaba & Astyanax lorien Zanata et al., 2018 & Characidae \\
\hline Bagre & Aspidoras psammatides Brito et al., 2005 & Callichthyidae \\
\hline Acará & Geophagus diamantinensis Mattos et al., 2015 & Cichlidae \\
\hline
\end{tabular}

De tudo exposto acima, fica evidente o caráter único do Marimbus, com uma área de $48 \mathrm{~km}^{2}$, cujas características ecológicas são semelhantes às encontradas no Pantanal Mato-grossense, que ocupa uma área de aproximadamente $100.000 \mathrm{Km}^{2}$. Deve-se se considerar que essa região está situada em pleno bioma Caatinga, tradicionalmente relacionado ao clima semiárido. 
Embora ainda faltem estudos em uma série de grupos ecológicos, essas características diferenciadas aumentam a biodiversidade regional $e$ oferecem refúgio a muitas espécies que não dispõem de outros habitat, com destaque para as espécies endêmicas da sub-bacia, especialmente no caso dos peixes que ocorrem ali.

\section{Recomendações}

Os dados apresentados neste texto indicam que há a necessidade de uma ação mais criteriosa para a concessão de outorgas d'água na sub-bacia do rio Santo Antônio. Essa consideração vale também para outras sub-bacias, mas a conservação do Marimbus faz que seja imprescindível a definição de parâmetros mais rígidos quanto ao uso d'água, além de levar em consideração as estações fluviométricas e pluviométricas já existentes nos processos autorizativos. Vale frisar, novamente, que os dados estão disponíveis, na maioria dos casos, na internet. Além disso, estudos que avaliem o uso e a ocupação do solo e a conservação da mata ciliar são fundamentais para o planejamento da ocupação do solo nas áreas circunvizinhas aos cursos d'água.

A redução na vazão do rio Santo Antônio indicada neste estudo pode ser transitória, em função da seca prolongada que entre 2012 e 2017 (Lima \& Magalhães, 2018), ou pode ser resultado das alterações antrópicas já presentes na sub-bacia. Na falta de um estudo que demonstre um ou outro fator como causa, o princípio da precaução manda que sejam suspensas as outorgas já concedidas visando garantir as vazões ecológicas mínimas.

Por fim, um estudo mais aprofundado do comportamento do rio Santo Antônio e de seus afluentes e das consequências para o Marimbus deve ser realizado o mais rápido possível para dar base a um programa de manejo da microbacia que garanta a conservação da biota local, especialmente com foco nas espécies endêmicas de animais, como peixes, principalmente.

\section{Referências}

ANA. Estação convencional 51190000, Ponte de Ligação Andaraí - BR 242. < http://www.snirh.gov.br/ hidroweb/serieshistoricas > . Acesso em: 17/12/2020.
Alves BCC, Souza Filho FA \& Silveira CS. Análise de Tendências e Padrões de Variação das Séries Históricas de Vazões do Operador Nacional do Sistema (ONS). Revista Brasileira de Recursos Hídricos, 18(4): 19-34. 2013.

Aranzabal IA \& Oliveira CAD. A gestão pública das águas e os conflitos territoriais na Bacia Hidrográfica do rio Paraguaçu. 2019. < https://cptba.org.br/wp-content/ uploads/2019/11/Artigo-Paragua\%C3\%A7u.pdf. > Acesso em: 14/04/2021.

Aulete. Marimbu. Aulete Dicionário Digital. <https:// www.aulete.com.br/marimbu. > Acesso em: 12/04/2020.

Ávila PLR \& Brito JIB. Relação entre a Oscilação Decadal do Pacifico e a variabilidade de precipitação de Campina Grande, PB. Ciência \& Natura, 37: 159162. 2015.

Ayres M, Ayres Jr M, Ayres DL \& Santos AAS. 2007. Bioestat 5.3. Aplicações estatísticas nas áreas das ciências biológicas e médicas. IDSM. 384p.

Carvalho CJR. 2000. Ecofisiologia do dendezeiro (Elaeis guineensis Jacq.), p. 89-124. In: Viégas JM \& Müller AA. A cultura do dendezeiro na Amazônia brasileira. $1 \mathrm{Ed}$. Embrapa, 320p.

Chen D, Cane MA, Kaplan A, Zebiak SE \& Huang D. Predictability of El Niño over the past 148 years. Nature, 428(15): 733-736. 2004.

CONAMA. 2005. Resolução no 357, de 17 de março de 2005. Diário Oficial da União. <http://www2.mma.gov. $\mathrm{br} /$ port/conama/legiabre.cfm?codlegi $=459>$. Acesso em: 20/03/2021.

CONAMA. 1994. Resolução ${ }^{\circ} 5$, de 4 de maio de 1994. Diário Oficial da União. <http://www2.mma. gov.br/port/conama/legiabre.cfm?codlegi $=146>$. Acesso em : 04/04/2021.

Couto APL, Funch LS \& Conceição AA. Composição florística e fisionomia de floresta estacional semidecídua submontana na Chapada Diamantina, Bahia, Brasil. Rodriguésia, 61(2): 391-405. 2011.

CPRM. 1994. Projeto Chapada Diamantina. Parque Nacional da Chapada Diamantina - BA. Informações básica para gestão territorial: diagnóstico do meio físico e da vegetação. $1 \mathrm{Ed}$. CPRM - IBAMA. 104p.

França F, Melo E, Oliveira IB, Reis ATCV, Alves GL \& Costa MF. Plantas vasculares das áreas alagadas dos Marimbus, Chapada Diamantina, BA, Brasil. Hoehnea, 37(4): 719-730. 2010.

Godinho LR \& Santos ACA. Dieta de duas espécies de peixes da família Cichlidae (Astronotus ocellatus e Cichla pinima) introduzidos no rio Paraguaçu, Bahia. Biotemas, 27: 83-91. 2014. 
Gonçalves CN \& Azevedo-Gonçalves CF. 2016. Estrutura de populações relictuais e resiliência de buritis no parque Nacional da Chapada Diamantina e entorno, com sugestões de ações para a conservação da espécie. p. 36-47. In: Gonçalves CN \& Azevêdo-Gonçalves CFA (orgs.). Aspectos Botânicos e Ecológicos em Comunidades da Chapada Diamantina. 1ed. Novas Edições Acadêmicas. 141p.

Guimarães Rosa J. 1956. Grande Sertão Veredas. 1 ed. Livraria José Olympio Editora. 602p.

ICMBio. 2007. Plano de Manejo do Parque Nacional da Chapada Diamantina. ICMBIO. 506p.

INMET. 2020. Estação: Lençóis (83242). Tabela de Dados Meteorológicos. Disponível em: https://tempo.inmet.gov. br/TabelaEstacoes/83242. Acesso em: 18/12/2020.

Kayano MT, Andreoli RV, Souza RAF, Garcia SR \& Calheiros AJP. 2016. El Niño e La Niña dos últimos 30 anos: diferentes tipos. Revista Climanálise. Edição comemorativa de 30 anos do Climanálise. <http:// climanalise.cptec.inpe.br/ rclimanl/revista/pdf/30anos/ Kayanoetal.pdf.> Acesso em: 30/03/2021.

Lima JR \& Magalhães AR. Secas no Nordeste: registros históricos das catástrofes econômicas e humanas do século 16 ao século 21. Parcerias Estratégicas, 23(46): 191-212. 2018.

Lima NRG, Paula A, Soares Filho AO, Gonçalves CN \& Guimarães VFG. 2016. Florística e estrutura de dois fragmentos de floresta estacional semidecidual do Parque Nacional da Chapada Diamantina, Andaraí - Bahia. p. 36-47. In: Gonçalves CN \& Azevêdo-Gonçalves CFA (orgs.). Aspectos Botânicos e Ecológicos em Comunidades da Chapada Diamantina. 1Ed. Novas Edições Acadêmicas. 141p.

Lima ACP, França F \& Jesus TB. Avaliação dos níveis de metais pesados no pantanal dos Marimbus, Bahia, Brasil. Engenharia Sanitária e Ambiental, 23(3): 591-598. 2018.

Magalhães FM, Laranjeiras DO, Costa TB, Juncá FA, Mesquita DO, Röhr DO, Silva WP, Vieira GHC \& Garda AA. Herpetofauna of protected areas in the Caatinga IV: Chapada Diamantina National Park, Bahia, Brazil. Herpetology Notes, 8: 243-261. 2015.

Marimbus. Pantanal dos Marimbus. 2015. <http:// marimbus.com.br/o-pantanal/> . Acesso em: 22/04/2021.
Molion LCB. Aquecimento global, el niños, manchas solares, vulcões e oscilação decadal do pacífico. Revista Climanálise, 3(1): 1-5. 2005.

Mortatti J, Bortoletto Júnior MJ, Milde LCE \& Probst J. Hidrologia dos Rios Tietê e Piracicaba: séries temporais de vazão e hidrogramas de cheia. Revista de Ciência \& Tecnologia, 12(23): 55-67. 2014.

Oliveira CD. Os territórios camponeses na Bacia Hidrográfica do rio Paraguaçu, na Bahia-Brasil e as ameaças pela política agronegócio. Diálogos Textos breves sobre desarrollo rural solicitados por el IPDRS, 212: 1-5. 2018. <https://ipdrs.org/images/dialogos/ archivos/Dialogos_212.pdf $>$. Acesso em: 22/04/2021.

Parrini R, Raposo MA, Pacheco JF, Carvalháes AMP, Melo Júnior TA, Fonseca PS \& Minns J. Birds of the Chapada Diamantina, Bahia, Brazil. Cotinga, 11: 86-95. 1999.

Pereira SB, Pruski FF, Silva DD \& Ramos MM. Estudo do comportamento hidrológico do Rio São Francisco $e$ seus principais afluentes. Revista Brasileira de Engenharia Agrícola e Ambiental, 11(6): 615-622. 2007.

Ramos GJP, Bicudo CEM, Góes-Neto A \& Santana CWN. Hydrodictyaceae (Chlorophyceae, Chlorophyta) do Pantanal dos Marimbus, Chapada Diamantina, Bahia, Brasil. Iheringia, Série Botânica, 71(1): 13-21. 2016.

Santos ACA \& Caramaschi EP. Composition and Seasonal Variation of the Ichthyofauna from Upper Rio Paraguaçu (Chapada Diamantina, Bahia, Brazil). Brazilian Archives of Biology and Technology, 50: 663-672. 2007.

Sarmento-Soares LM, Santos ACA \& MartinsPinheiro RF. Rios e peixes do Paraguaçu na Chapada Diamantina: conservação e perspectivas. BSBI, 134: 16-57. 2020.

SEI. Mapa da Bacia do Rio Paraguaçu. <www.seia. ba.gov.br>. Acesso em: 04/04/2021.

Venturieri A, Fernandes WR, Boari AJ \& Vasconcelos MA. 2009. Relação entre ocorrência do amarelecimento fatal do dendezeiro (Elaeis guineensis Jacq.) e variáveis ambientais no estado do Pará. p. 523-530. In: Anais XIV Simpósio Brasileiro de Sensoriamento Remoto, Natal. 7954p. 
Anexo 1 - Tabela de parâmetros da estação fluviométrica 51190000, localizada próximo à ponte do Fertém, rio Santo Antônio, município de Andaraí. Os dados estão de acordo com que consta no site http:// www.snirh.gov.br/hidroweb/, tendo sido eliminados os registros em duplicidade e os dados de coleta redundantes (mais de uma coleta diária). Prof. = profundidade.

\begin{tabular}{|c|c|c|c|c|c|c|c|c|}
\hline $\begin{array}{c}\text { Nível } \\
\text { consistência }\end{array}$ & Data & $\begin{array}{c}\mathbf{N}^{\circ} \\
\text { medição }\end{array}$ & Cota & Vazão & $\begin{array}{c}\text { Área } \\
\text { molhada }\end{array}$ & Largura & Vel. media & Prof. \\
\hline 1 & $30 / 08 / 1947$ & 1 & 64 & 4.14 & 19.1 & 34.6 & 0.217 & 0.55 \\
\hline 1 & $12 / 05 / 1948$ & 2 & 90 & 20.2 & 38.5 & 49.2 & 0.525 & 0.78 \\
\hline 1 & $12 / 05 / 1948$ & 3 & 90 & 19.1 & 36.7 & 49.2 & 0.52 & 0.75 \\
\hline 1 & $10 / 05 / 1949$ & 4 & 92 & 19.8 & 41 & 49 & 0.482 & 0.84 \\
\hline 1 & 04/08/1949 & 5 & 66 & 10.5 & 32 & 48.5 & 0.328 & 0.66 \\
\hline 1 & 04/08/1949 & 6 & 66 & 10.5 & 30.8 & 48.5 & 0.341 & 0.64 \\
\hline 1 & $20 / 07 / 1950$ & 7 & 88 & 14.1 & 25.14 & 49.1 & 0.562 & 0.51 \\
\hline 1 & $20 / 07 / 1950$ & 8 & 88 & 13.4 & 25.2 & 49.1 & 0.532 & 0.51 \\
\hline 1 & $27 / 11 / 1950$ & 9 & 99 & 20.2 & 38.71 & 49.38 & 0.522 & 0.78 \\
\hline 1 & $27 / 11 / 1950$ & 10 & 99 & 19.7 & 38.03 & 49.38 & 0.518 & 0.77 \\
\hline 1 & 29/05/1951 & 11 & 132 & 34.5 & 53.61 & 59.87 & 0.644 & 0.56 \\
\hline 1 & $23 / 05 / 1952$ & 12 & 111 & 18.7 & 36.78 & 50.13 & 0.507 & 0.73 \\
\hline 1 & 19/09/1952 & 13 & 59 & 2.74 & 7.11 & 38.82 & 0.386 & 0.18 \\
\hline 1 & 19/09/1952 & 14 & 59 & 2.87 & 7.13 & 38.82 & 0.403 & 0.18 \\
\hline 1 & 08/12/1955 & 15 & 186 & 76.1 & 121.3 & 146.85 & 0.628 & 0.83 \\
\hline 1 & 19/07/1958 & 16 & 106 & 20.2 & 36.24 & 46.86 & 0.557 & 0.77 \\
\hline 1 & 19/07/1958 & 17 & 106 & 19.1 & 35.65 & 46.86 & 0.536 & 0.76 \\
\hline 1 & 10/06/1959 & 18 & 71 & 3.18 & 18.9 & 39.38 & 0.168 & 0.48 \\
\hline 1 & 10/06/1959 & 19 & 71 & 3.44 & 18.76 & 39.38 & 0.183 & 0.48 \\
\hline 1 & $11 / 05 / 1960$ & 20 & 138 & 35.5 & 64.03 & 78.1 & 0.554 & 0.82 \\
\hline 1 & $11 / 05 / 1960$ & 21 & 137 & 35.7 & 59.67 & 78.1 & 0.598 & 0.76 \\
\hline 1 & 09/12/1961 & 22 & 66 & 5.37 & 25.62 & 39.81 & 0.209 & 0.64 \\
\hline 1 & 09/12/1961 & 23 & 69 & 5.77 & 25.56 & 39.81 & 0.226 & 0.64 \\
\hline 1 & $12 / 12 / 1961$ & 24 & 84 & 17.7 & 29.4 & 42.8 & 0.642 & 0.69 \\
\hline 1 & 09/11/1962 & 25 & 49 & 0.88 & 18.9 & 33.95 & 0.047 & 0.56 \\
\hline 1 & $13 / 05 / 1964$ & 26 & 157 & 59 & 82.9 & 71.8 & 0.712 & 1.15 \\
\hline 1 & $20 / 05 / 1964$ & 27 & 158 & 59.6 & 85.4 & 73 & 0.698 & 1.17 \\
\hline 1 & $26 / 05 / 1964$ & 28 & 140 & 43.3 & 71.3 & 71 & 0.607 & 1 \\
\hline 1 & $26 / 05 / 1964$ & 29 & 140 & 47.5 & 73.7 & 71 & 0.644 & 1.04 \\
\hline 1 & 02/06/1964 & 30 & 127 & 30.9 & 64.1 & 71 & 0.482 & 0.9 \\
\hline 1 & 29/06/1964 & 31 & 129 & 43.3 & 71.6 & 71 & 0.605 & 1.01 \\
\hline 1 & $29 / 06 / 1964$ & 32 & 129 & 42.3 & 70.2 & 71 & 0.602 & 0.99 \\
\hline 1 & 06/07/1964 & 33 & 105 & 27.8 & 57.1 & 69.9 & 0.486 & 0.82 \\
\hline 1 & 06/07/1964 & 34 & 105 & 28.6 & 58.1 & 69.9 & 0.492 & 0.83 \\
\hline 1 & $10 / 07 / 1964$ & 35 & 98 & 24.7 & 50.5 & 70.2 & 0.489 & 0.72 \\
\hline 1 & $11 / 07 / 1964$ & 36 & 96 & 22.6 & 49.4 & 69.8 & 0.457 & 0.71 \\
\hline 1 & $11 / 07 / 1964$ & 37 & 95 & 23 & 46.2 & 69.8 & 0.498 & 0.66 \\
\hline
\end{tabular}




\begin{tabular}{|c|c|c|c|c|c|c|c|c|}
\hline 1 & $17 / 07 / 1964$ & 38 & 93 & 20.5 & 42.8 & 69.7 & 0.479 & 0.61 \\
\hline 1 & $17 / 07 / 1964$ & 39 & 93 & 21 & 43.6 & 69.7 & 0.482 & 0.62 \\
\hline 1 & 04/08/1964 & 40 & 99 & 23.4 & 56 & 69.7 & 0.418 & 0.8 \\
\hline 1 & 04/08/1964 & 41 & 100 & 25.9 & 53 & 69.7 & 0.489 & 0.76 \\
\hline 1 & 07/08/1964 & 42 & 96 & 24.1 & 50.8 & 69.5 & 0.474 & 0.73 \\
\hline 1 & 07/08/1964 & 43 & 96 & 23.2 & 50.4 & 69.5 & 0.46 & 0.72 \\
\hline 1 & $26 / 08 / 1964$ & 44 & 96 & 24.7 & 49.8 & 69.9 & 0.496 & 0.72 \\
\hline 1 & $26 / 08 / 1964$ & 45 & 96 & 24 & 48.9 & 69.9 & 0.491 & 0.7 \\
\hline 1 & 01/09/1964 & 46 & 84 & 16 & 39 & 69.5 & 0.41 & 0.56 \\
\hline 1 & 01/09/1964 & 47 & 84 & 15.7 & 38.5 & 69.5 & 0.408 & 0.56 \\
\hline 1 & 01/01/1965 & 48 & 97 & 26.4 & 48.4 & 69.4 & 0.545 & 0.7 \\
\hline 1 & 08/01/1965 & 49 & 91 & 25.3 & 45.4 & 70 & 0.557 & 0.65 \\
\hline 1 & 08/01/1965 & 50 & 91 & 24.8 & 46.7 & 70 & 0.531 & 0.67 \\
\hline 1 & 09/02/1965 & 51 & 74 & 11.2 & 30.8 & 51.5 & 0.364 & 0.6 \\
\hline 1 & 09/02/1965 & 52 & 74 & 11 & 30.5 & 51 & 0.361 & 0.6 \\
\hline 1 & $15 / 02 / 1965$ & 53 & 72 & 10.8 & 30.6 & 52.5 & 0.353 & 0.58 \\
\hline 1 & $15 / 02 / 1965$ & 54 & 72 & 10.3 & 30.7 & 52.5 & 0.336 & 0.58 \\
\hline 1 & 01/03/1965 & 55 & 66 & 16.2 & 25.56 & 34.1 & 0.638 & 0.75 \\
\hline 1 & $13 / 03 / 1965$ & 56 & 60 & 6.32 & 20.9 & 57.5 & 0.302 & 0.36 \\
\hline 1 & $13 / 03 / 1965$ & 57 & 60 & 6.29 & 22.5 & 57.5 & 0.279 & 0.39 \\
\hline 1 & $19 / 03 / 1965$ & 58 & 57 & 5.48 & 11.8 & 16 & 0.464 & 0.74 \\
\hline 1 & $19 / 03 / 1965$ & 59 & 57 & 5.38 & 11.8 & 20.2 & 0.456 & 0.58 \\
\hline 1 & $23 / 03 / 1965$ & 60 & 56 & 5.72 & 9.85 & 20.2 & 0.581 & 0.49 \\
\hline 1 & $23 / 03 / 1965$ & 61 & 56 & 5.61 & 12 & 20.2 & 0.467 & 0.59 \\
\hline 1 & $30 / 03 / 1965$ & 62 & 65 & 10.1 & 26.5 & 58 & 0.381 & 0.46 \\
\hline 1 & $30 / 03 / 1965$ & 63 & 65 & 10 & 26.9 & 57.5 & 0.372 & 0.47 \\
\hline 1 & $01 / 04 / 1965$ & 64 & 82 & 17.5 & 36.7 & 58.7 & 0.477 & 0.62 \\
\hline 1 & $01 / 04 / 1965$ & 65 & 83 & 17.5 & 36.3 & 58.7 & 0.477 & 0.62 \\
\hline 1 & $10 / 04 / 1965$ & 66 & 148 & 70.9 & 94.8 & 72.1 & 0.748 & 1.31 \\
\hline 1 & $17 / 04 / 1965$ & 67 & 224 & 136 & 168 & 171 & 0.809 & 0.98 \\
\hline 1 & $19 / 04 / 1965$ & 68 & 205 & 123 & 143 & 112 & 0.86 & 1.28 \\
\hline 1 & $19 / 04 / 1965$ & 69 & 200 & 115 & 138 & 112 & 0.833 & 1.23 \\
\hline 1 & $20 / 04 / 1965$ & 70 & 220 & 143 & 155 & 162 & 0.922 & 0.96 \\
\hline 1 & $26 / 04 / 1965$ & 71 & 156 & 68.4 & 93 & 73 & 0.735 & 1.27 \\
\hline 1 & $26 / 04 / 1965$ & 72 & 156 & 70.4 & 96.3 & 73 & 0.731 & 1.32 \\
\hline 1 & $30 / 04 / 1965$ & 73 & 122 & 37.8 & 67.8 & 71 & 0.557 & 0.95 \\
\hline 1 & $30 / 04 / 1965$ & 74 & 122 & 36.7 & 66.6 & 71 & 0.551 & 0.94 \\
\hline 1 & $04 / 05 / 1965$ & 75 & 102 & 24.4 & 53.5 & 71 & 0.456 & 0.75 \\
\hline 1 & 04/05/1965 & 76 & 102 & 24.6 & 53 & 71 & 0.456 & 0.75 \\
\hline 1 & 07/05/1965 & 77 & 128 & 44.1 & 72.5 & 72 & 0.608 & 1 \\
\hline 1 & 07/05/1965 & 78 & 128 & 44 & 72.1 & 72 & 0.608 & 1 \\
\hline 1 & $15 / 05 / 1965$ & 79 & 106 & 30.2 & 56.8 & 70.1 & 0.532 & 0.81 \\
\hline
\end{tabular}




\begin{tabular}{|c|c|c|c|c|c|c|c|c|}
\hline 1 & $15 / 05 / 1965$ & 80 & 106 & 28.9 & 73.8 & 70.1 & 0.391 & 1.05 \\
\hline 1 & $19 / 05 / 1965$ & 81 & 90 & 18.7 & 45.1 & 70.5 & 0.415 & 0.64 \\
\hline 1 & 19/05/1965 & 82 & 90 & 17.2 & 43.6 & 70.5 & 0.394 & 0.62 \\
\hline 1 & $25 / 05 / 1965$ & 83 & 78 & 12.1 & 36 & 70.5 & 0.336 & 0.51 \\
\hline 1 & 25/05/1965 & 84 & 78 & 12.2 & 36.5 & 70.5 & 0.334 & 0.52 \\
\hline 1 & 28/05/1965 & 85 & 74 & 9.13 & 32.5 & 44.5 & 0.281 & 0.73 \\
\hline 1 & 28/05/1965 & 86 & 74 & 9.14 & 32.6 & 44.5 & 0.28 & 0.73 \\
\hline 1 & $31 / 05 / 1965$ & 87 & 121 & 39.7 & 66 & 71.5 & 0.601 & 0.92 \\
\hline 1 & $31 / 05 / 1965$ & 88 & 121 & 40.2 & 66.7 & 71.5 & 0.603 & 0.93 \\
\hline 1 & 02/07/1965 & 89 & 149 & 57.4 & 78.2 & 71 & 0.734 & 1.1 \\
\hline 1 & 02/07/1965 & 90 & 153 & 60.2 & 77.1 & 71.5 & 0.781 & 1.08 \\
\hline 1 & 17/07/1965 & 91 & 94 & 19.9 & 42.2 & 70 & 0.471 & 0.6 \\
\hline 1 & 17/07/1965 & 92 & 93 & 20.2 & 40.9 & 69.8 & 0.494 & 0.59 \\
\hline 1 & 04/08/1965 & 93 & 121 & 34.3 & 55.6 & 71 & 0.617 & 0.78 \\
\hline 1 & 04/08/1965 & 94 & 120 & 33.4 & 55.2 & 71 & 0.605 & 0.78 \\
\hline 1 & 22/10/1965 & 95 & 112 & 33 & 58.5 & 70.5 & 0.564 & 0.83 \\
\hline 1 & 22/10/1965 & 96 & 112 & 32.5 & 59.2 & 70.5 & 0.549 & 0.84 \\
\hline 1 & 07/11/1965 & 97 & 132 & 48.3 & 73.7 & 71 & 0.655 & 1.04 \\
\hline 1 & 07/11/1965 & 98 & 132 & 47.4 & 73.1 & 71 & 0.648 & 1.03 \\
\hline 1 & 26/11/1965 & 99 & 144 & 54.3 & 77.2 & 71.9 & 0.703 & 1.07 \\
\hline 1 & 26/11/1965 & 100 & 144 & 55.1 & 77.3 & 71.9 & 0.713 & 1.07 \\
\hline 1 & 13/03/1966 & 101 & 134 & 52.2 & 80.11 & 71.53 & 0.651 & 1.12 \\
\hline 1 & 13/03/1966 & 102 & 134 & 51.5 & 79.87 & 71.53 & 0.645 & 1.12 \\
\hline 1 & 02/04/1966 & 103 & 91 & 19.9 & 51.5 & 69.3 & 0.386 & 0.74 \\
\hline 1 & 02/04/1966 & 104 & 91 & 20.2 & 51 & 69.3 & 0.396 & 0.73 \\
\hline 1 & 21/06/1966 & 105 & 99 & 22.2 & 47.8 & 65 & 0.464 & 0.73 \\
\hline 1 & 19/09/1966 & 106 & 64 & 6.42 & 32.21 & 49.2 & 0.199 & 0.65 \\
\hline 1 & 19/09/1966 & 107 & 64 & 6.33 & 32.1 & 49.2 & 0.197 & 0.65 \\
\hline 1 & $17 / 01 / 1967$ & 108 & 74 & 11.2 & 40.41 & 70.1 & 0.278 & 0.58 \\
\hline 1 & 17/01/1967 & 109 & 74 & 10.9 & 39.65 & 70.1 & 0.275 & 0.57 \\
\hline 1 & 20/01/1967 & 110 & 76 & 12.5 & 42.75 & 70.15 & 0.292 & 0.61 \\
\hline 1 & $20 / 01 / 1967$ & 111 & 76 & 12.5 & 42.74 & 70.15 & 0.292 & 0.61 \\
\hline 1 & 27/01/1967 & 112 & 71 & 10.2 & 36.67 & 69.55 & 0.279 & 0.53 \\
\hline 1 & 27/01/1967 & 113 & 71 & 10.1 & 36.71 & 69.55 & 0.276 & 0.53 \\
\hline 1 & 01/02/1967 & 114 & 69 & 7.81 & 33.2 & 52 & 0.235 & 0.64 \\
\hline 1 & 02/02/1967 & 115 & 68 & 10.6 & 36.09 & 70.6 & 0.293 & 0.51 \\
\hline 1 & 02/02/1967 & 116 & 68 & 9.8 & 36.45 & 70.6 & 0.269 & 0.52 \\
\hline 1 & 05/02/1967 & 117 & 67 & 8.97 & 34.79 & 67.79 & 0.258 & 0.51 \\
\hline 1 & 05/02/1967 & 118 & 67 & 9.33 & 34.69 & 67.79 & 0.269 & 0.51 \\
\hline 1 & 09/02/1967 & 119 & 68 & 9.42 & 30.31 & 65.41 & 0.311 & 0.46 \\
\hline 1 & 09/02/1967 & 120 & 68 & 9.16 & 30.07 & 65.41 & 0.304 & 0.46 \\
\hline 1 & 02/03/1967 & 121 & 76 & 12.6 & 43.66 & 70.69 & 0.287 & 0.62 \\
\hline
\end{tabular}




\begin{tabular}{|c|c|c|c|c|c|c|c|c|}
\hline 1 & 02/03/1967 & 122 & 76 & 12.4 & 44.69 & 70.69 & 0.278 & 0.63 \\
\hline 1 & $10 / 03 / 1967$ & 123 & 67 & 8.08 & 36.77 & 69.98 & 0.22 & 0.53 \\
\hline 1 & $10 / 03 / 1967$ & 124 & 67 & 8.13 & 36.58 & 69.98 & 0.222 & 0.52 \\
\hline 1 & $17 / 03 / 1967$ & 125 & 56 & 6.5 & 29.65 & 59.96 & 0.219 & 0.49 \\
\hline 1 & $17 / 03 / 1967$ & 126 & 56 & 6.6 & 29.48 & 59.96 & 0.224 & 0.49 \\
\hline 1 & 05/04/1967 & 127 & 133 & 57.5 & 84.41 & 71.35 & 0.681 & 1.18 \\
\hline 1 & 05/04/1967 & 128 & 132 & 58.1 & 86.44 & 71.37 & 0.672 & 1.21 \\
\hline 1 & $12 / 04 / 1967$ & 129 & 116 & 42.5 & 71.58 & 70.5 & 0.594 & 1.02 \\
\hline 1 & $12 / 04 / 1967$ & 130 & 116 & 43.9 & 70.59 & 70.5 & 0.622 & 1 \\
\hline 1 & 29/05/1967 & 131 & 63 & 7.1 & 30.5 & 54 & 0.232 & 0.56 \\
\hline 1 & 29/05/1967 & 132 & 63 & 7.19 & 31.2 & 54 & 0.23 & 0.58 \\
\hline 1 & 31/03/1968 & 133 & 135 & 50.6 & 81 & 65 & 0.625 & 1.25 \\
\hline 1 & $31 / 03 / 1968$ & 134 & 134 & 48.5 & 78.9 & 65 & 0.614 & 1.21 \\
\hline 1 & $31 / 03 / 1968$ & 135 & 134 & 46.8 & 76.9 & 65 & 0.608 & 1.18 \\
\hline 1 & $31 / 03 / 1968$ & 136 & 133 & 48 & 77.1 & 65 & 0.622 & 1.19 \\
\hline 1 & 01/04/1968 & 137 & 129 & 42.9 & 72.8 & 65 & 0.589 & 1.12 \\
\hline 1 & 01/04/1968 & 138 & 128 & 43.1 & 72.3 & 65 & 0.596 & 1.11 \\
\hline 1 & $16 / 01 / 1969$ & 139 & 76 & 7.94 & 29.4 & 66.1 & 0.27 & 0.44 \\
\hline 1 & $16 / 01 / 1969$ & 140 & 76 & 8.49 & 29.28 & 66.1 & 0.29 & 0.44 \\
\hline 1 & $15 / 04 / 1969$ & 141 & 120 & 38.6 & 66.05 & 70.5 & 0.584 & 0.94 \\
\hline 1 & $15 / 04 / 1969$ & 142 & 120 & 39.3 & 64.12 & 70.5 & 0.613 & 0.91 \\
\hline 1 & $24 / 05 / 1969$ & 143 & 128 & 43.1 & 67.2 & 70 & 0.641 & 0.96 \\
\hline 1 & 24/05/1969 & 144 & 126 & 42.7 & 67 & 70 & 0.637 & 0.96 \\
\hline 1 & 25/06/1969 & 145 & 124 & 38.8 & 56.67 & 69.55 & 0.685 & 0.81 \\
\hline 1 & $25 / 06 / 1969$ & 146 & 123 & 38.3 & 57.08 & 69.55 & 0.671 & 0.82 \\
\hline 1 & 26/08/1969 & 147 & 74 & 10.5 & 59.46 & 64.45 & 0.356 & 0.46 \\
\hline 1 & 26/08/1969 & 148 & 74 & 10.6 & 29.59 & 64.45 & 0.359 & 0.46 \\
\hline 1 & $17 / 10 / 1969$ & 149 & 70 & 9.75 & 29.9 & 64.04 & 0.326 & 0.47 \\
\hline 1 & $17 / 10 / 1969$ & 150 & 71 & 10.6 & 30.11 & 64.08 & 0.352 & 0.47 \\
\hline 1 & 03/11/1969 & 151 & 60 & 6.58 & 23.2 & 47 & 0.283 & 0.49 \\
\hline 1 & $15 / 11 / 1969$ & 152 & 58 & 5.56 & 25.9 & 51.2 & 0.215 & 0.51 \\
\hline 1 & $15 / 11 / 1969$ & 153 & 58 & 5.63 & 25.97 & 51.2 & 0.217 & 0.51 \\
\hline 1 & 23/02/1970 & 154 & 122 & 43 & 68.54 & 69.6 & 0.627 & 0.98 \\
\hline 1 & 23/02/1970 & 155 & 122 & 44.6 & 70.3 & 69.6 & 0.635 & 1.01 \\
\hline 1 & 28/02/1970 & 156 & 152 & 56.9 & 75.5 & 71 & 0.754 & 1.06 \\
\hline 1 & 28/02/1970 & 157 & 152 & 56.3 & 75.2 & 71 & 0.749 & 1.06 \\
\hline 1 & 02/04/1970 & 158 & 92 & 17.7 & 37.9 & 83 & 0.467 & 0.46 \\
\hline 1 & 02/04/1970 & 159 & 92 & 18 & 38.2 & 83 & 0.471 & 0.46 \\
\hline 1 & 29/08/1970 & 160 & 83 & 17.5 & 39.4 & 73.5 & 0.444 & 0.54 \\
\hline 1 & 29/08/1970 & 161 & 83 & 17.9 & 39.4 & 73.5 & 0.454 & 0.54 \\
\hline 1 & 03/11/1970 & 162 & 100 & 28.9 & 58.76 & 71.25 & 0.492 & 0.82 \\
\hline 1 & 03/11/1970 & 163 & 102 & 28.2 & 56.53 & 71.25 & 0.498 & 0.79 \\
\hline
\end{tabular}




\begin{tabular}{|c|c|c|c|c|c|c|c|c|}
\hline 1 & 29/11/1970 & 164 & 176 & 84.3 & 110 & 76.5 & 0.766 & 1.44 \\
\hline 1 & 29/11/1970 & 165 & 176 & 82.3 & 106 & 76.5 & 0.776 & 1.38 \\
\hline 1 & $16 / 12 / 1970$ & 166 & 121 & 41.7 & 66.3 & 72 & 0.629 & 0.92 \\
\hline 1 & $16 / 12 / 1970$ & 167 & 121 & 43.4 & 67 & 72 & 0.648 & 0.93 \\
\hline 1 & 23/12/1970 & 168 & 115 & 33.8 & 65.9 & 82 & 0.513 & 0.8 \\
\hline 1 & 23/12/1970 & 169 & 115 & 34 & 65.5 & 82 & 0.519 & 0.8 \\
\hline 1 & 28/12/1970 & 170 & 99 & 23.5 & 48.8 & 84 & 0.481 & 0.58 \\
\hline 1 & 28/12/1970 & 171 & 99 & 23 & 48.8 & 84 & 0.471 & 0.58 \\
\hline 1 & 07/01/1971 & 172 & 80 & 14 & 32 & 83 & 0.437 & 0.38 \\
\hline 1 & 07/01/1971 & 173 & 80 & 14.3 & 31.1 & 83 & 0.459 & 0.37 \\
\hline 1 & 12/02/1971 & 174 & 66 & 9.02 & 24.8 & 60 & 0.363 & 0.4 \\
\hline 1 & 12/02/1971 & 175 & 66 & 8.9 & 24.8 & 60 & 0.359 & 0.4 \\
\hline 1 & 26/09/1971 & 176 & 60 & 9.34 & 28.6 & 54.5 & 0.327 & 0.52 \\
\hline 1 & 21/11/1971 & 177 & 182 & 81.3 & 120.1 & 75.8 & 0.677 & 1.58 \\
\hline 1 & $21 / 11 / 1971$ & 178 & 177 & 76.5 & 166.2 & 75.8 & 0.658 & 1.53 \\
\hline 1 & 08/12/1971 & 179 & 88 & 21.8 & 61.23 & 69.1 & 0.356 & 0.88 \\
\hline 1 & 08/12/1971 & 180 & 88 & 19.9 & 53.4 & 69.1 & 0.373 & 0.77 \\
\hline 1 & 08/12/1971 & 179 & 88 & 21.8 & 61.23 & 69.1 & 0.356 & 0.88 \\
\hline 1 & 08/12/1971 & 180 & 88 & 19.9 & 53.4 & 69.1 & 0.373 & 0.77 \\
\hline 1 & 07/01/1972 & 181 & 68 & 10.8 & 40 & 68.3 & 0.269 & 0.58 \\
\hline 1 & 07/01/1972 & 182 & 68 & 9.52 & 39.03 & 68.3 & 0.244 & 0.57 \\
\hline 1 & 03/02/1972 & 183 & 72 & 11.9 & 43.06 & 68.8 & 0.277 & 0.62 \\
\hline 1 & 03/02/1972 & 184 & 72 & 13.9 & 43.58 & 68.8 & 0.318 & 0.63 \\
\hline 1 & 20/02/1972 & 185 & 136 & 51.1 & 79.2 & 68.5 & 0.645 & 1.15 \\
\hline 1 & 26/02/1972 & 186 & 84 & 17 & 42.6 & 67.5 & 0.399 & 0.63 \\
\hline 1 & 26/02/1972 & 187 & 84 & 17 & 42.8 & 67.5 & 0.397 & 0.63 \\
\hline 1 & 05/03/1972 & 188 & 92 & 20.5 & 47.2 & 68 & 0.434 & 0.69 \\
\hline 1 & 05/03/1972 & 189 & 92 & 20.6 & 47 & 68 & 0.438 & 0.69 \\
\hline 1 & 07/03/1972 & 190 & 82 & 14.7 & 43.5 & 68.8 & 0.339 & 0.63 \\
\hline 1 & 07/03/1972 & 191 & 82 & 15.4 & 44.3 & 68.8 & 0.348 & 0.64 \\
\hline 1 & $11 / 04 / 1972$ & 192 & 72 & 10.6 & 10.6 & 68.5 & 0.293 & 0.53 \\
\hline 1 & $11 / 04 / 1972$ & 193 & 72 & 10.9 & 10.9 & 68.5 & 0.288 & 0.55 \\
\hline 1 & $10 / 05 / 1972$ & 194 & 58 & 5.09 & 5.09 & 64.4 & 0.201 & 0.39 \\
\hline 1 & $10 / 05 / 1972$ & 195 & 58 & 5.69 & 5.69 & 64.4 & 0.221 & 0.39 \\
\hline 1 & 08/06/1972 & 196 & 139 & 50.1 & 50.1 & 71 & 0.631 & 1.11 \\
\hline 1 & 08/06/1972 & 197 & 138 & 49.7 & 49.7 & 71 & 0.618 & 1.13 \\
\hline 1 & $11 / 07 / 1972$ & 198 & 75 & 13.5 & 13.5 & 68 & 0.343 & 0.58 \\
\hline 1 & $11 / 07 / 1972$ & 199 & 75 & 12.8 & 12.8 & 68 & 0.32 & 0.58 \\
\hline 1 & 05/08/1972 & 200 & 71 & 10.3 & 10.3 & 67.6 & 0.317 & 0.48 \\
\hline 1 & 05/08/1972 & 201 & 71 & 10.6 & 10.6 & 67.6 & 0.327 & 0.48 \\
\hline 1 & 14/09/1972 & 202 & 86 & 16.5 & 44.62 & 72 & 0.364 & 0.62 \\
\hline 1 & 14/09/1972 & 203 & 86 & 17.5 & 46.08 & 72 & 0.378 & 0.64 \\
\hline
\end{tabular}




\begin{tabular}{|c|c|c|c|c|c|c|c|c|}
\hline 1 & 06/10/1972 & 204 & 72 & 10.4 & 10.4 & 68 & 0.304 & 0.5 \\
\hline 1 & 06/10/1972 & 205 & 72 & 9.83 & 9.83 & 68 & 0.287 & 0.5 \\
\hline 1 & 07/11/1972 & 206 & 59 & 6.24 & 6.24 & 68 & 0.213 & 0.42 \\
\hline 1 & 07/11/1972 & 207 & 59 & 6.35 & 6.35 & 68 & 0.228 & 0.4 \\
\hline 1 & $11 / 12 / 1972$ & 208 & 67 & 8.13 & 8.13 & 68 & 0.263 & 0.45 \\
\hline 1 & $11 / 12 / 1972$ & 209 & 66 & 8.66 & 8.66 & 68 & 0.282 & 0.45 \\
\hline 1 & $23 / 01 / 1973$ & 210 & 130 & 44.4 & 44.4 & 70 & 0.642 & 0.98 \\
\hline 1 & $23 / 01 / 1973$ & 211 & 130 & 44.8 & 44.8 & 70 & 0.638 & 1 \\
\hline 1 & 07/02/1973 & 212 & 68 & 8.32 & 8.32 & 68.35 & 0.286 & 0.42 \\
\hline 1 & 07/02/1973 & 213 & 68 & 8.58 & 28.76 & 68.35 & 0.298 & 0.42 \\
\hline 1 & $24 / 02 / 1973$ & 214 & 75 & 11.3 & 34.98 & 68.75 & 0.323 & 0.5 \\
\hline 1 & $24 / 02 / 1973$ & 215 & 74 & 12.2 & 34.94 & 68.75 & 0.35 & 0.5 \\
\hline 1 & 06/03/1973 & 216 & 59 & 6.89 & 24.68 & 68.2 & 0.279 & 0.36 \\
\hline 1 & 06/03/1973 & 217 & 59 & 6.44 & 25.04 & 68.2 & 0.257 & 0.36 \\
\hline 1 & $18 / 03 / 1973$ & 218 & 159 & 64.3 & 97.32 & 73 & 0.661 & 1.33 \\
\hline 1 & 18/03/1973 & 219 & 157 & 62.5 & 98.43 & 73 & 0.635 & 1.34 \\
\hline 1 & $12 / 04 / 1973$ & 220 & 121 & 43 & 65.45 & 71.5 & 0.657 & 0.91 \\
\hline 1 & $12 / 04 / 1973$ & 221 & 120 & 41.3 & 64.9 & 71.5 & 0.636 & 0.9 \\
\hline 1 & $17 / 05 / 1973$ & 222 & 102 & 26.6 & 49.26 & 71.9 & 0.541 & 0.68 \\
\hline 1 & $17 / 05 / 1973$ & 223 & 101 & 24.6 & 47.75 & 71.9 & 0.517 & 0.66 \\
\hline 1 & 09/06/1973 & 224 & 130 & 46.3 & 71.62 & 70.3 & 0.647 & 1.01 \\
\hline 1 & 09/06/1973 & 225 & 130 & 45.3 & 69.4 & 70.3 & 0.652 & 0.98 \\
\hline 1 & $21 / 07 / 1973$ & 226 & 106 & 25.1 & 53.51 & 69.8 & 0.469 & 0.76 \\
\hline 1 & $21 / 07 / 1973$ & 227 & 106 & 25.5 & 53.78 & 69.8 & 0.475 & 0.77 \\
\hline 1 & $17 / 08 / 1973$ & 228 & 71 & 10.4 & 26.47 & 69 & 0.394 & 0.38 \\
\hline 1 & $17 / 08 / 1973$ & 229 & 71 & 10.1 & 26.26 & 69 & 0.384 & 0.38 \\
\hline 1 & $17 / 09 / 1973$ & 230 & 59 & 4.85 & 22.78 & 68.6 & 0.213 & 0.33 \\
\hline 1 & 19/09/1973 & 231 & 59 & 4.81 & 22.88 & 74.6 & 0.21 & 0.3 \\
\hline 1 & $18 / 01 / 1974$ & 232 & 95 & 18.6 & 47.23 & 69 & 0.394 & 0.68 \\
\hline 1 & 18/01/1974 & 233 & 94 & 19.3 & 48.09 & 69 & 0.401 & 0.69 \\
\hline 1 & $27 / 01 / 1974$ & 234 & 116 & 33.8 & 65.49 & 69.8 & 0.516 & 0.93 \\
\hline 1 & $27 / 01 / 1974$ & 235 & 116 & 35.4 & 66.91 & 69.3 & 0.53 & 0.96 \\
\hline 1 & $19 / 02 / 1974$ & 236 & 138 & 41.3 & 72.63 & 69.4 & 0.568 & 1.06 \\
\hline 1 & $23 / 04 / 1974$ & 237 & 162 & 63.2 & 92.28 & 71 & 0.685 & 1.29 \\
\hline 1 & $22 / 05 / 1974$ & 238 & 174 & 88.5 & 105.6 & 72.15 & 0.839 & 1.46 \\
\hline 1 & $16 / 06 / 1974$ & 239 & 132 & 50.5 & 80.3 & 70.55 & 0.629 & 1.13 \\
\hline 1 & $26 / 07 / 1974$ & 240 & 111 & 26.1 & 59.49 & 69.1 & 0.439 & 0.86 \\
\hline 1 & $22 / 08 / 1974$ & 241 & 86 & 13.3 & 39.66 & 76.5 & 0.336 & 0.51 \\
\hline 1 & 17/10/1974 & 242 & 129 & 39.3 & 75.08 & 70.3 & 0.524 & 1.06 \\
\hline 1 & $14 / 12 / 1974$ & 243 & 187 & 94.2 & 127.4 & 78 & 0.74 & 1.63 \\
\hline 1 & 20/02/1975 & 244 & 113 & 27.6 & 65.98 & 70 & 0.419 & 0.94 \\
\hline 1 & $21 / 04 / 1975$ & 245 & 151 & 56.9 & 96.22 & 71.1 & 0.592 & 1.35 \\
\hline
\end{tabular}




\begin{tabular}{|c|c|c|c|c|c|c|c|c|}
\hline 1 & $16 / 06 / 1975$ & 246 & 78 & 10.7 & 48.2 & 68.15 & 0.223 & 0.7 \\
\hline 1 & $15 / 08 / 1975$ & 247 & 104 & 23.9 & 62.02 & 70.1 & 0.386 & 0.88 \\
\hline 1 & 22/10/1975 & 248 & 76 & 10.9 & 43.5 & 68.5 & 0.25 & 0.63 \\
\hline 1 & $16 / 12 / 1975$ & 249 & 107 & 29.1 & 67.64 & 70.55 & 0.43 & 0.95 \\
\hline 1 & 21/01/1976 & 250 & 67 & 6.96 & 37.48 & 68.2 & 0.186 & 0.55 \\
\hline 1 & 21/05/1976 & 251 & 73 & 8.95 & 40.62 & 68.85 & 0.22 & 0.59 \\
\hline 2 & $21 / 05 / 1976$ & 252 & 73 & 9.49 & 42.7 & 68.85 & 0.222 & 0.62 \\
\hline 2 & $21 / 07 / 1976$ & 253 & 65 & 7.16 & 34.49 & 64.9 & 0.208 & 0.53 \\
\hline 2 & 19/11/1976 & 254 & 209 & 98.9 & 137.9 & 82.4 & 0.717 & 1.67 \\
\hline 2 & 23/01/1977 & 255 & 129 & 41.8 & 72.76 & 71 & 0.574 & 1.02 \\
\hline 2 & 21/03/1977 & 256 & 73 & 9.27 & 33.08 & 64.2 & 0.28 & 0.52 \\
\hline 2 & $21 / 04 / 1977$ & 257 & 78 & 12 & 37.94 & 65.5 & 0.316 & 0.58 \\
\hline 2 & 23/07/1977 & 258 & 91 & 17.3 & 45.61 & 66.3 & 0.379 & 0.69 \\
\hline 2 & 13/09/1977 & 259 & 61 & 5.08 & 26.83 & 64.8 & 0.189 & 0.41 \\
\hline 2 & 13/11/1977 & 260 & 86 & 15.6 & 48.16 & 67.5 & 0.324 & 0.71 \\
\hline 2 & 26/02/1978 & 261 & 165 & 60.5 & 108.6 & 71.3 & 0.557 & 1.52 \\
\hline 2 & 09/05/1978 & 262 & 161 & 61.5 & 100.6 & 69 & 0.612 & 1.46 \\
\hline 2 & $15 / 08 / 1978$ & 263 & 139 & 43.1 & 77.52 & 69 & 0.556 & 1.12 \\
\hline 2 & 19/11/1978 & 264 & 155 & 60.4 & 99.95 & 69.8 & 0.604 & 1.43 \\
\hline 2 & $14 / 02 / 1979$ & 265 & 176 & 82.7 & 121.4 & 77.5 & 0.681 & 1.57 \\
\hline 2 & $14 / 05 / 1979$ & 266 & 107 & 25.1 & 62.48 & 65.2 & 0.402 & 0.96 \\
\hline 2 & 19/07/1979 & 267 & 92 & 15.8 & 47.37 & 62 & 0.334 & 0.76 \\
\hline 2 & 15/09/1979 & 268 & 71 & 7.96 & 34.49 & 61 & 0.231 & 0.57 \\
\hline 2 & 14/11/1979 & 269 & 142 & 47.6 & 80.35 & 69.5 & 0.592 & 1.16 \\
\hline 2 & 18/07/1980 & 270 & 102 & 23.1 & 55.3 & 59 & 0.418 & 0.94 \\
\hline 2 & $11 / 11 / 1980$ & 271 & 93 & 3.48 & 43.08 & 56.3 & 0.081 & 0.77 \\
\hline 2 & 12/03/1981 & 272 & 89 & 17.6 & 52.43 & 65.5 & 0.336 & 0.8 \\
\hline 2 & 12/03/1981 & 273 & 89 & 17.5 & 52.43 & 65.5 & 0.335 & 0.8 \\
\hline 2 & 18/09/1981 & 274 & 71 & 7.84 & 42.63 & 65.3 & 0.184 & 0.65 \\
\hline 2 & 14/12/1981 & 275 & 71 & 8.54 & 35.34 & 63.7 & 0.242 & 0.55 \\
\hline 2 & 16/02/1982 & 276 & 132 & 46.8 & 53.77 & 71.8 & 0.87 & 0.75 \\
\hline 2 & $17 / 02 / 1982$ & 277 & 174 & 87.3 & 121.1 & 77 & 0.721 & 1.57 \\
\hline 2 & $17 / 05 / 1982$ & 278 & 91 & 19.9 & 61.39 & 66 & 0.324 & 0.93 \\
\hline 2 & 17/05/1982 & 279 & 91 & 20 & 61.39 & 66 & 0.274 & 1.06 \\
\hline 2 & 20/11/1982 & 280 & 59 & 4.82 & 36.51 & 64.5 & 0.132 & 0.57 \\
\hline 2 & $16 / 02 / 1983$ & 281 & 168 & 69 & 117.1 & 71.6 & 0.589 & 1.64 \\
\hline 2 & 20/05/1983 & 282 & 111 & 31.6 & 65.44 & 69.5 & 0.484 & 0.94 \\
\hline 2 & $15 / 08 / 1983$ & 283 & 62 & 5.83 & 29.86 & 63.5 & 0.195 & 0.47 \\
\hline 2 & 18/11/1983 & 284 & 107 & 29 & 59.13 & 68.4 & 0.497 & 0.86 \\
\hline 2 & 15/02/1984 & 285 & 54 & 4.66 & 21.86 & 62 & 0.213 & 0.35 \\
\hline 2 & 24/05/1984 & 286 & 125 & 37.4 & 77.41 & 70 & 0.483 & 1.1 \\
\hline 2 & $18 / 08 / 1984$ & 287 & 61 & 6.82 & 29.9 & 62 & 0.228 & 0.48 \\
\hline
\end{tabular}




\begin{tabular}{|c|c|c|c|c|c|c|c|c|}
\hline 2 & 24/11/1984 & 288 & 70 & 9.97 & 32.56 & 65 & 0.306 & 0.5 \\
\hline 2 & 04/03/1985 & 289 & 138 & 43.48 & 88 & 69.5 & 0.494 & 1.27 \\
\hline 2 & $28 / 05 / 1985$ & 290 & 100 & 20 & 48.24 & 65.2 & 0.414 & 0.74 \\
\hline 2 & $12 / 08 / 1985$ & 291 & 119 & 32.52 & 65.4 & 68.5 & 0.497 & 0.95 \\
\hline 2 & 18/11/1985 & 292 & 160 & 61.8 & 90.4 & 70 & 0.683 & 1.29 \\
\hline 2 & $21 / 02 / 1986$ & 293 & 89 & 15.6 & 53.96 & 59.5 & 0.288 & 0.92 \\
\hline 2 & 27/05/1986 & 294 & 79 & 11.8 & 34.7 & 61.5 & 0.34 & 0.56 \\
\hline 2 & 27/05/1986 & 295 & 79 & 11.8 & 34.7 & 61.5 & 0.34 & 0.56 \\
\hline 2 & $25 / 08 / 1986$ & 296 & 92 & 18.7 & 38.61 & 65 & 0.484 & 0.59 \\
\hline 2 & 22/11/1986 & 297 & 130 & 37.4 & 72.47 & 68 & 0.516 & 1.07 \\
\hline 2 & $21 / 02 / 1987$ & 298 & 60 & 5.38 & 22.1 & 63 & 0.243 & 0.35 \\
\hline 2 & $26 / 05 / 1987$ & 299 & 85 & 14.9 & 44.92 & 66.3 & 0.332 & 0.68 \\
\hline 2 & $28 / 08 / 1987$ & 300 & 49 & 3.23 & 20.76 & 62 & 0.156 & 0.33 \\
\hline 2 & 28/08/1987 & 301 & 49 & 3.32 & 20.9 & 62 & 0.159 & 0.34 \\
\hline 2 & $28 / 08 / 1987$ & 302 & 49 & 3.2 & 20.76 & 62 & 0.154 & 0.33 \\
\hline 2 & $28 / 08 / 1987$ & 303 & 49 & 3.3 & 20.9 & 62 & 0.158 & 0.34 \\
\hline 2 & $17 / 11 / 1987$ & 304 & 45 & 2.57 & 18.56 & 63.2 & 0.139 & 0.29 \\
\hline 2 & $17 / 11 / 1987$ & 305 & 45 & 2.45 & 18.92 & 63.2 & 0.129 & 0.3 \\
\hline 2 & $26 / 02 / 1988$ & 306 & 44 & 2.63 & 11.21 & 61.5 & 0.235 & 0.18 \\
\hline 2 & $26 / 02 / 1988$ & 307 & 44 & 2.79 & 11.82 & 61.9 & 0.236 & 2.19 \\
\hline 2 & $28 / 03 / 1988$ & 308 & 140 & 45.5 & 88.05 & 67.9 & 0.517 & 1.3 \\
\hline 2 & $25 / 02 / 1989$ & 309 & 49 & 3.26 & 13.2 & 60.5 & 0.247 & 0.22 \\
\hline 2 & $25 / 02 / 1989$ & 310 & 49 & 3.76 & 13.31 & 60.5 & 0.244 & 0.23 \\
\hline 2 & $28 / 03 / 1989$ & 311 & 77 & 11.7 & 32.07 & 63.8 & 0.365 & 0.5 \\
\hline 2 & $16 / 12 / 1991$ & 312 & 111 & 20.9 & 57.9 & 68.5 & 0.38 & 0.85 \\
\hline 2 & $16 / 12 / 1991$ & 313 & 111 & 20.8 & 58.83 & 68.5 & 0.353 & 0.86 \\
\hline 2 & 05/08/1992 & 314 & 106 & 22.9 & 53.1 & 69 & 0.431 & 0.77 \\
\hline 2 & $18 / 11 / 1992$ & 315 & 75 & 9.76 & 35.4 & 68 & 0.276 & 0.5 \\
\hline 2 & $25 / 03 / 1993$ & 316 & 51 & 3.78 & 17.7 & 63 & 0.214 & 0.28 \\
\hline 2 & 25/03/1993 & 317 & 51 & 3.78 & 18.1 & 63 & 0.209 & 0.29 \\
\hline 2 & $31 / 08 / 1993$ & 318 & 51 & 3.79 & 17.9 & 63 & 0.211 & 0.28 \\
\hline 2 & $31 / 08 / 1993$ & 319 & 51 & 3.81 & 17.8 & 63 & 0.214 & 0.28 \\
\hline 2 & $11 / 11 / 1993$ & 320 & 43 & 1.82 & 12.27 & 62 & 0.148 & 0.2 \\
\hline 2 & 11/11/1993 & 321 & 43 & 1.97 & 13.73 & 62 & 0.143 & 0.22 \\
\hline 2 & $18 / 02 / 1994$ & 322 & 45 & 2.3 & 16.4 & 62 & 0.14 & 0.26 \\
\hline 2 & $18 / 02 / 1994$ & 323 & 45 & 2.27 & 16.2 & 62 & 0.14 & 0.26 \\
\hline 2 & 26/05/1994 & 324 & 79 & 12.1 & 31.6 & 65.6 & 0.382 & 0.48 \\
\hline 2 & 26/05/1994 & 322 & 79 & 12.1 & 31.6 & 65.6 & 0.382 & 0.48 \\
\hline 2 & $26 / 05 / 1994$ & 324 & 79 & 12.1 & 31.6 & 65.6 & 0.382 & 0.48 \\
\hline 2 & 03/08/1994 & 325 & 92 & 17.2 & 41.8 & 68.9 & 0.412 & 0.61 \\
\hline 2 & $17 / 10 / 1994$ & 326 & 46 & 2.43 & 15.8 & 62 & 0.154 & 0.25 \\
\hline 2 & $12 / 04 / 1995$ & 327 & 59 & 7.23 & 22.1 & 63.2 & 0.327 & 0.35 \\
\hline
\end{tabular}




\begin{tabular}{|c|c|c|c|c|c|c|c|c|}
\hline 2 & $12 / 04 / 1995$ & 328 & 59 & 6.85 & 21.5 & 63.2 & 0.319 & 0.34 \\
\hline 2 & 20/07/1995 & 329 & 110 & 25 & 60.3 & 68 & 0.414 & 0.89 \\
\hline 2 & 17/10/1995 & 330 & 38 & 1.21 & 18.4 & 62.6 & 0.066 & 0.29 \\
\hline 2 & 20/02/1996 & 331 & 41 & 2.34 & 22.6 & 64 & 0.103 & 0.35 \\
\hline 2 & 20/02/1996 & 332 & 41 & 2.5 & 22.4 & 64 & 0.112 & 0.35 \\
\hline 2 & 23/04/1996 & 333 & 45 & 2.87 & 23.47 & 64 & 1 & 0.37 \\
\hline 2 & 23/04/1996 & 334 & 45 & 2.92 & 23.21 & 64 & 0.126 & 0.36 \\
\hline 2 & 23/04/1996 & 335 & 49 & 3.5 & 25.05 & 64 & 0.14 & 0.39 \\
\hline 2 & 12/10/1996 & 336 & 68 & 8.09 & 38.46 & 64.8 & 0.21 & 0.59 \\
\hline 2 & 10/11/1996 & 337 & 47 & 2.78 & 26.15 & 62.6 & 0.106 & 0.42 \\
\hline 2 & 19/02/1997 & 338 & 138 & 35.3 & 76.84 & 69.4 & 0.459 & 1.11 \\
\hline 2 & 19/02/1997 & 339 & 138 & 35.6 & 74.6 & 69.4 & 0.477 & 1.07 \\
\hline 2 & 28/04/1997 & 340 & 160 & 41.8 & 112.9 & 70.8 & 0.37 & 1.59 \\
\hline 2 & 19/06/1997 & 341 & 114 & 19.7 & 70.7 & 67.9 & 0.278 & 1.04 \\
\hline 2 & 19/06/1997 & 342 & 114 & 20.2 & 71 & 67.9 & 0.284 & 1.05 \\
\hline 2 & 09/09/1997 & 343 & 66 & 4.89 & 38.29 & 65.3 & 0.128 & 0.59 \\
\hline 2 & 09/09/1997 & 344 & 66 & 4.99 & 36.97 & 65.3 & 0.135 & 0.57 \\
\hline 2 & 14/11/1997 & 345 & 60 & 3.92 & 35.42 & 65 & 0.111 & 0.54 \\
\hline 2 & 14/11/1997 & 346 & 60 & 4.06 & 35.64 & 65 & 0.114 & 0.55 \\
\hline 2 & $18 / 02 / 1998$ & 347 & 126 & 30.8 & 67.84 & 68.2 & 0.454 & 0.99 \\
\hline 2 & $18 / 02 / 1998$ & 348 & 129 & 34.5 & 69.82 & 68.2 & 0.494 & 1.02 \\
\hline 2 & $27 / 05 / 1998$ & 349 & 52 & 3.66 & 12.52 & 63.5 & 0.293 & 0.2 \\
\hline 2 & $27 / 05 / 1998$ & 350 & 52 & 3.66 & 12.52 & 63.5 & 0.293 & 0.2 \\
\hline 2 & $27 / 05 / 1998$ & 351 & 52 & 3.66 & 12.52 & 63.5 & 0.293 & 0.2 \\
\hline 2 & $26 / 11 / 1998$ & 352 & 223 & 71.5 & 146 & 221.6 & 0.49 & 0.66 \\
\hline 2 & 26/11/1998 & 353 & 222 & 76.2 & 147 & 221.6 & 0.517 & 0.67 \\
\hline 2 & 27/11/1998 & 354 & 186 & 58.5 & 105 & 70 & 0.555 & 1.51 \\
\hline 2 & $25 / 02 / 1999$ & 355 & 118 & 24.1 & 58 & 66.3 & 0.417 & 0.87 \\
\hline 2 & 29/05/1999 & 356 & 87 & 11.8 & 35.6 & 64.6 & 0.331 & 0.55 \\
\hline 2 & 29/05/1999 & 357 & 87 & 12 & 35.9 & 64.6 & 0.334 & 0.56 \\
\hline 2 & 03/09/1999 & 358 & 129 & 30.2 & 69.5 & 66 & 0.434 & 1.05 \\
\hline 2 & 03/09/1999 & 359 & 130 & 31.1 & 70.4 & 66 & 0.441 & 1.07 \\
\hline 2 & 25/11/1999 & 360 & 219 & 78.8 & 143 & 85.4 & 0.553 & 1.67 \\
\hline 2 & 26/11/1999 & 361 & 180 & 60.2 & 112 & 68.6 & 0.536 & 1.64 \\
\hline 2 & 26/11/1999 & 362 & 179 & 58.4 & 112 & 68.6 & 0.524 & 1.63 \\
\hline 2 & $17 / 02 / 2000$ & 363 & 106 & 16.2 & 53.8 & 66.9 & 0.301 & 0.8 \\
\hline 2 & $17 / 02 / 2000$ & 364 & 106 & 15.8 & 54.6 & 66.9 & 0.289 & 0.82 \\
\hline 2 & $28 / 04 / 2000$ & 365 & 139 & 32.9 & 69 & 67.7 & 0.476 & 1.02 \\
\hline 2 & 28/04/2000 & 366 & 138 & 33.1 & 69.6 & 67.7 & 0.475 & 1.02 \\
\hline 2 & $11 / 07 / 2000$ & 367 & 122 & 25.3 & 55.5 & 67.2 & 0.456 & 0.83 \\
\hline 2 & $11 / 07 / 2000$ & 368 & 122 & 27.2 & 59.4 & 67.2 & 0.457 & 0.88 \\
\hline 2 & $05 / 12 / 2000$ & 369 & 76 & 9 & 32.57 & 68 & 0.29 & 0.47 \\
\hline
\end{tabular}




\begin{tabular}{|c|c|c|c|c|c|c|c|c|}
\hline 2 & $25 / 01 / 2001$ & 370 & 89 & 13 & 35.37 & 65.5 & 0.361 & 0.54 \\
\hline 2 & $13 / 06 / 2001$ & 371 & 110 & 20 & 46.6 & 66 & 0.439 & 0.71 \\
\hline 2 & $19 / 09 / 2001$ & 372 & 71 & 8 & 22.08 & 64.7 & 0.34 & 0.34 \\
\hline 2 & $19 / 09 / 2001$ & 373 & 71 & 8 & 22.62 & 64.7 & 0.336 & 0.35 \\
\hline 2 & $11 / 12 / 2001$ & 374 & 115 & 24 & 53.1 & 67 & 0.458 & 0.79 \\
\hline 2 & $30 / 01 / 2002$ & 375 & 145 & 36 & 83.96 & 67 & 0.429 & 1.25 \\
\hline 2 & $01 / 05 / 2002$ & 376 & 82 & 11 & 28.6 & 65 & 0.381 & 0.44 \\
\hline 2 & 06/08/2002 & 377 & 70 & 6 & 20.43 & 64.5 & 0.307 & 0.32 \\
\hline 2 & $22 / 10 / 2002$ & 378 & 57 & 3 & 16.12 & 65 & 0.207 & 0.25 \\
\hline 2 & 03/02/2003 & 379 & 155 & 33 & 76.3 & 67.6 & 0.433 & 1.13 \\
\hline 2 & 03/02/2003 & 380 & 155 & 34 & 75.07 & 67.6 & 0.459 & 1.11 \\
\hline 2 & 05/07/2003 & 381 & 80 & 10 & 27.51 & 65.2 & 0.373 & 0.41 \\
\hline 2 & 05/07/2003 & 382 & 80 & 10 & 27.38 & 55.3 & 0.358 & 0.49 \\
\hline 2 & $31 / 10 / 2003$ & 383 & 50 & 2 & 15.33 & 65.9 & 0.162 & 0.23 \\
\hline 2 & $02 / 08 / 2004$ & 384 & 64 & 7 & 17.34 & 63.4 & 0.384 & 0.27 \\
\hline 2 & $02 / 08 / 2004$ & 385 & 67 & 6.51 & 17.33 & 63.4 & 0.376 & 0.27 \\
\hline 2 & $16 / 10 / 2004$ & 386 & 44 & 2 & 8.53 & 33.5 & 0.207 & 0.25 \\
\hline 2 & $16 / 10 / 2004$ & 387 & 44 & 2 & 8.74 & 33.5 & 0.2 & 0.26 \\
\hline 2 & $15 / 06 / 2005$ & 388 & 160 & 49 & 82.15 & 67.8 & 0.596 & 1.21 \\
\hline 2 & $17 / 09 / 2005$ & 389 & 74 & 9 & 26.3 & 66.2 & 0.355 & 0.4 \\
\hline 2 & $14 / 10 / 2006$ & 390 & 66 & 6 & 17.23 & 48 & 0.323 & 0.36 \\
\hline 2 & $16 / 07 / 2007$ & 391 & 128 & 27 & 63.38 & 66.4 & 0.43 & 0.96 \\
\hline 2 & $16 / 07 / 2007$ & 392 & 128 & 28 & 64.34 & 66.4 & 0.44 & 0.97 \\
\hline 2 & $17 / 11 / 2007$ & 393 & 48 & 2 & 16.51 & 33 & 0.1 & 0.5 \\
\hline 2 & $17 / 11 / 2007$ & 394 & 48 & 2 & 17.63 & 33.6 & 0.114 & 0.52 \\
\hline 2 & $01 / 07 / 2008$ & 395 & 108 & 20 & 59.53 & 65 & 0.335 & 0.92 \\
\hline 2 & $14 / 10 / 2008$ & 396 & 55 & 3 & 26.82 & 65.3 & 0.103 & 0.41 \\
\hline 2 & $14 / 10 / 2008$ & 397 & 55 & 3 & 24.57 & 65.3 & 0.111 & 0.39 \\
\hline 2 & $18 / 05 / 2009$ & 398 & 108 & 20 & 49.8 & 64.3 & 0.408 & 0.77 \\
\hline 2 & $29 / 08 / 2009$ & 399 & 68 & 7 & 17.43 & 66 & 0.381 & 0.26 \\
\hline 2 & $17 / 03 / 2010$ & 400 & 58 & 3.94 & 19.7 & 65 & 0.2 & 0.3 \\
\hline 2 & $17 / 03 / 2010$ & 401 & 58 & 3.93 & 20.2 & 65 & 0.194 & 0.31 \\
\hline 2 & 21/09/2010 & 402 & 57 & 3 & 15.53 & 32.5 & 0.19 & 0.48 \\
\hline 2 & 21/09/2010 & 403 & 57 & 3 & 15.63 & 32.5 & 0.197 & 0.48 \\
\hline 2 & $21 / 09 / 2010$ & 404 & 57 & 3 & 16 & 32.5 & 0.19 & 0.48 \\
\hline 2 & $15 / 08 / 2011$ & 406 & 77 & 7 & 24 & 70.8 & 0.302 & 0.35 \\
\hline 2 & $14 / 11 / 2011$ & 407 & 168 & 40 & 82.47 & 68 & 0.488 & 1.21 \\
\hline 2 & 14/11/2011 & 408 & 167 & 43 & 81 & 68 & 0.533 & 1.19 \\
\hline 2 & $26 / 03 / 2012$ & 409 & 39 & 1 & 7 & 18.6 & 0.194 & 0.4 \\
\hline 2 & $26 / 03 / 2012$ & 410 & 39 & 1 & 7 & 18.6 & 0.201 & 0.39 \\
\hline 2 & 03/08/2012 & 411 & 59 & 2 & 10 & 19.3 & 0.238 & 0.52 \\
\hline 2 & 03/08/2012 & 412 & 59 & 2.31 & 10 & 19.3 & 0.232 & 0.52 \\
\hline
\end{tabular}




\begin{tabular}{|c|c|c|c|c|c|c|c|c|}
\hline 2 & 03/08/2012 & 413 & 59 & 2 & 10.22 & 19.3 & 0.221 & 0.53 \\
\hline 2 & $22 / 11 / 2012$ & 414 & 62 & 5.96 & 17 & 65.3 & 0.342 & 0.27 \\
\hline 2 & $22 / 11 / 2012$ & 415 & 62 & 4.82 & 18 & 65.3 & 0.266 & 0.28 \\
\hline 2 & 08/03/2013 & 416 & 39 & 2 & 6 & 26 & 0.266 & 0.24 \\
\hline 2 & 08/03/2013 & 417 & 39 & 2 & 6 & 26 & 0.271 & 0.24 \\
\hline 2 & $15 / 07 / 2013$ & 418 & 85 & 10 & 29.6 & 65 & 0.342 & 0.46 \\
\hline 2 & $15 / 07 / 2013$ & 419 & 85 & 10 & 30.11 & 65 & 0.338 & 0.46 \\
\hline 2 & $15 / 07 / 2013$ & 420 & 85 & 9 & 29 & 65 & 0.32 & 0.45 \\
\hline 2 & 08/10/2013 & 421 & 53 & 3 & 9 & 24.5 & 0.278 & 0.38 \\
\hline 2 & 08/10/2013 & 422 & 53 & 2 & 9 & 24.5 & 0.281 & 0.36 \\
\hline 2 & 08/10/2013 & 423 & 53 & 1.9 & 8.49 & 24.5 & 0.224 & 0.35 \\
\hline 2 & 02/06/2014 & 424 & 82 & 8 & 22 & 66.2 & 0.348 & 0.34 \\
\hline 2 & 16/10/2014 & 425 & 40 & 0.746 & 7.37 & 19.5 & 0.101 & 0.38 \\
\hline 2 & 14/07/2015 & 427 & 130 & 23 & 49.13 & 67 & 0.463 & 0.73 \\
\hline 2 & 14/07/2015 & 428 & 129 & 22 & 47 & 67 & 0.466 & 0.7 \\
\hline 2 & 11/10/2015 & 429 & 43 & 2 & 5.05 & 20 & 0.312 & 0.25 \\
\hline 2 & $18 / 03 / 2016$ & 430 & 64 & 3 & 21 & 54.6 & 0.164 & 0.39 \\
\hline 2 & 04/08/2016 & 431 & 44 & 1.52 & 10 & 30 & 0.154 & 0.33 \\
\hline 2 & 05/04/2017 & 432 & 224 & 73 & 143 & 93.68 & 0.876 & 1.52 \\
\hline 2 & 17/07/2017 & 433 & 101 & 12 & 39 & 66.04 & 0.323 & 0.58 \\
\hline 2 & 26/10/2017 & 434 & 38 & 0.941 & 7.69 & 20.5 & 0.122 & 0.38 \\
\hline 2 & 07/03/2018 & 435 & 56 & 2.82 & 11.85 & 39 & 0.238 & 0.3 \\
\hline 2 & $18 / 08 / 2018$ & 436 & 56 & 2.86 & 10.9 & 20.08 & 0.261 & 0.54 \\
\hline
\end{tabular}

Biodiversidade Brasileira - BioBrasil.

Edição Temática: Análise de Componentes do Sistema Climático e a Biodiversidade no Brasil

$$
\text { n. 4, } 2021
$$

http://www.icmbio.gov.br/revistaeletronica/index.php/BioBR

Biodiversidade Brasileira é uma publicação eletrônica científica do Instituto Chico Mendes de

Conservação da Biodiversidade (ICMBio) que tem como objetivo fomentar a discussão e a disseminação de experiências em conservação e manejo, com foco em unidades de conservação $e$ espécies ameaçadas.

ISSN: 2236-2886 